\title{
Partidos Políticos, Ideologia e Política Social na América Latina: 1980-1999*
}

Cristiane Batista

\section{INTRODUÇÃO}

$\mathrm{O}$ mapa político da América Latina passa por profundas transformações. Após as eleições de Hugo Chávez, na Venezuela (2000 e 2006), de Luiz Inácio Lula da Silva, no Brasil (2002 e 2006), do casal Kirchner, na Argentina (2003 e 2007), de Tabaré Vazquez, no Uruguai (2004), de Evo Morales, na Bolívia (2005), e de Michelle Bachelet, no Chile (2006), podemos notar uma guinada à esquerda do espectro ideológico da região. Nos países andinos, a população indígena, parcela marginalizada da vida política ao longo de décadas, ganha destaque na pauta de discussão. A nova agenda política que começa a se fortalecer na América Latina se apresenta como alternativa àquela até então predominante, pautada na reforma estrutural, pró-mercado, e propõe uma maior atenção aos temas do crescimento econômico e da diminuição da pobreza e da desigualdade social. Diante dessa nova realidade, estaria o continente latino-americano passando por uma onda vermelha?

A discussão sobre distinção ideológica entre partidos políticos, ou entre governos, se pensarmos de forma mais geral, não é recente. Grande

\footnotetext{
* Agradeço a Octavio Amorim Neto e a Acir Almeida a leitura precisa e os inestimáveis comentários. Agradeço também as valiosas sugestões dos pareceristas anônimos da revista $D A D O S$, fundamentais para o aperfeiçoamento do presente artigo.
}

DADOS - Revista de Ciências Sociais, Rio de Janeiro, Vol. 51, nº3, 2008, pp. 647 a 686. 
parte das análises de resultados de políticas públicas inclui em suas investigações o impacto da inclinação ideológica do governo e da força desse governo no Legislativo sobre a implementação de tais políticas. O principal objetivo desses estudos é descobrir se a posição do governo no espectro ideológico e sua composição no Legislativo - majoritária ou minoritária - influenciam as linhas de políticas públicas adotadas por ele.

A existência de diferença ideológica entre partidos políticos é bastante questionada pela literatura. Parte dela sustenta que partidos de esquerda, considerados pro-welfare, quando no governo, gastam mais do que partidos de direita em políticas sociais. Segundo essa literatura, em países governados por partidos de esquerda, os gastos com bemestar social são mais elevados, ao passo que países governados por partidos de direita têm os gastos nessas áreas reduzidos (Hicks e Swank, 1984). Estudos direcionados ao contexto norte-americano atestam que existe diferença entre a condução de políticas macroeconômicas e fiscais desempenhadas por governos democratas e aquelas executadas por governos republicanos (Alesina e Rosenthal, 1995; Tufte, 1978). Contudo, outra vertente da literatura argumenta que partidos políticos fazem diferença, mas apenas moderadamente. Ou seja, mudanças na composição partidária do governo não estão associadas a mudanças instantâneas na orientação das políticas (Blais, Blake e Dion, 1993).

O debate em torno da relevância da ideologia e dos partidos políticos tomou dimensões ainda maiores na década de 1980, com o advento da globalização. Afinal, o intenso processo de internacionalização dos mercados, dos sistemas produtivos e da tendência à unificação monetária, ao qual aderiram os países do continente americano em resposta à crise do petróleo da década anterior, resultou em uma perda da autonomia dos Estados nacionais e, conseqüentemente, da diferença programática entre partidos políticos? Parte da literatura que investiga os efeitos da globalização sobre as políticas públicas afirma que sim, a abertura comercial prejudicou a autonomia nacional e as alternativas de esquerda para o livre mercado. De acordo com essa vertente de investigação, no contexto globalizado, países governados por partidos à esquerda do espectro ideológico têm sua economia desorganizada, pois, ao contrário de países dominados por partidos mais à direita, convivem com taxas mais elevadas de inflação e de desemprego (Kitschelt, 1994; Piven, 1991; Iversen, 1996; Swenson, 1991; Scharpf, 1988). 
Por outro lado, diferente linha de investigação postula que a relação entre a força política de partidos de esquerda e as políticas econômicas de cunho socialdemocrata não foi enfraquecida pela globalização, apesar das mudanças impostas por esta (Garrett, 1998; Boix, 1997). A globalização, ao contrário, aumentou os incentivos políticos para que partidos de esquerda promovessem a redistribuição da riqueza e do risco, além de ações direcionadas para pobres e trabalhadores a fim de protegê-los da insegurança causada pela maior exposição à competição entre mercados (Garrett, 1998).

A maioria dos estudos que se propõem a investigar o impacto da globalização nas políticas públicas se restringe, em geral, ao contexto europeu ou, em menor grau, ao contexto norte-americano. Para o contexto latino-americano, constata-se em algumas análises dos efeitos da globalização sobre a execução de políticas públicas que a maior exposição à competição internacional prejudicou os investimentos na área social e que, além disso, o impacto das variáveis domésticas - como tipo de regime e ideologia do governo - sobre o gasto social ocorre independentemente do efeito da globalização (Kaufman e Segura-Ubiergo, 2001) ${ }^{1}$. Outros autores, ao investigar se a integração econômica afetou a política de bem-estar social nos países da região, observam que diferentes indicadores de abertura comercial promovem resultados distintos, e que, portanto, a afirmação de que a globalização reduziu os investimentos na área social não é conclusiva (Avelino, Brown e Hunter, 2005) $)^{2}$.

Neste artigo, busco verificar se houve, no período inicial do processo de abertura comercial (meados da década de 1980 e início da década de 1990), variação nas políticas públicas adotadas pelos países da região e, em caso positivo, identificar os determinantes dessa variação. Como pudemos perceber, uma variável interveniente recorrente nas análises de políticas públicas diz respeito à inclinação ideológica dos partidos políticos que ocupam o poder. O viés ideológico dos governos da América Latina, afinal, é significativo a ponto de interferir no direcionamento das políticas públicas adotadas por eles em pleno processo de abertura comercial? Meu esforço neste estudo é, portanto, tentar identificar a relação entre ideologia do governo e políticas públicas em um período no qual a autonomia dos países na região foi posta em xeque.

Em virtude da forte relação existente na literatura entre esquerda e geração de política de bem-estar social, utilizo como indicador de políti- 
cas públicas o gasto público social, mais especificamente o gasto público em educação e saúde. Procuro identificar que atributos dos governos latino-americanos afetam o gasto social desempenhado por eles no período auge da abertura comercial, não deixando de considerar variáveis socioeconômicas também presentes na literatura pertinente.

Este artigo está estruturado em três seções. Na primeira seção, subdividida em duas partes, é apresentada a revisão da literatura a respeito dos determinantes políticos e econômicos do gasto social na Europa, nos Estados Unidos e na América Latina. Na segunda, encontram-se a elaboração das hipóteses de trabalho e a metodologia utilizada para análise do contexto latino-americano, assim como os testes estatísticos, tendo como unidade de análise quatorze países da região. Finalmente, na última seção, são oferecidas as principais conclusões deste estudo.

\section{OS DETERMINANTES POLÍTICOS DAS POLÍTICAS PÚBLICAS NA AMÉRICA LATINA}

Parte das pesquisas aplicadas ao continente latino-americano que se propõem a investigar o impacto das instituições domésticas sobre políticas públicas concentra suas análises no déficit fiscal e no gasto público dos países da região (Alesina et alii, 1999; Jones, Sanguinetti e Tommasi, 1999; Mejía Acosta e Coppedge, 2001; Amorim Neto e Borsani, 2004; Hallerberg e Marier, 2004). Uma variável recorrente nesses estudos se refere ao perfil ideológico dos governos. Afinal, partidos políticos podem ser ideologicamente distintos? As políticas públicas produzidas por governos de esquerda são diferentes das políticas públicas produzidas por governos de direita? Os principais achados dessas análises apontam para o fato de que os desempenhos econômico, político e social dos países desenvolvidos e/ou em desenvolvimento podem estar, sim, associados à globalização, mas não apenas. Correlacionam-se também com o perfil ideológico do governo e com sua coesão partidária no Legislativo.

A proposta do presente estudo é investigar se, na América Latina, a autonomia dos Estados nacionais foi prejudicada pelo advento da globalização, ocasionando homogeneização do padrão de políticas públicas adotadas por eles, ou se, ao contrário, é possível identificar uma variação de tais políticas em função da política e da economia domésticas, como o perfil ideológico do Executivo, bem como sua composição no 
Legislativo. Afinal, podemos dizer que a ideologia dos partidos no poder é fator determinante de política em pleno processo de abertura comercial? Partidos políticos fazem ou fizeram diferença para a execução de políticas públicas nas décadas de 1980 e 1990, período no qual teve início o processo de abertura comercial? Essas são as principais questões propostas neste artigo.

\section{A Importância da Ideologia e dos Partidos Políticos na Implementação de Políticas Públicas}

Como dito anteriormente, há, hoje, para o contexto latino-americano, uma diversidade de estudos que investigam o impacto das instituições políticas domésticas sobre o gasto público e o déficit fiscal (Alesina et alii, 1999; Jones, Sanguinetti e Tommasi, 1999; Mejía Acosta e Coppedge, 2001; Amorim Neto e Borsani, 2004; Hallerberg e Marier, 2004). Contudo, boa parte dessas análises atribui pouca importância à estrutura institucional e ao padrão de governança vigente na região. Estudo recente para a América Latina, desenvolvido por Mejía Acosta e Coppedge (2001), constitui uma exceção. Ao analisar os determinantes políticos da disciplina fiscal latino-americana, os autores defendem que esta depende da vontade dos governos; sendo assim, incorporam à análise aspectos institucionais e políticos específicos dos países da região. Sustentam, contudo, que os efeitos das variáveis institucionais sobre a disciplina fiscal (gasto público e déficit), como tamanho do partido do presidente, número efetivo de partidos, disciplina partidária, distância ideológica entre presidentes e legislaturas e polarização ideológica do sistema partidário, são maiores quando tais variáveis são interagidas.

Assim como Mejía Acosta e Coppedge (ibidem), Amorim Neto e Borsani (2004), em estudo sobre os determinantes políticos do gasto público e do déficit fiscal na América Latina, verificam que o efeito de algumas variáveis políticas sobre o gasto e o déficit é maior quando interagidas com outras variáveis. Os testes econométricos desenvolvidos pelos autores indicam que é a interação da força legislativa do presidente, da estabilidade ministerial e da ideologia do gabinete que vai determinar o nível do gasto dos países da região. Segundo o estudo desenvolvido por Amorim Neto e Borsani (ibidem), as características políticas dos governos latino-americanos influenciam significativamente tanto em seu gasto público quanto em seu comportamento fiscal.

Nessa mesma linha de análise, Huber, Mustillo e Stephens (2004), buscando verificar os efeitos de variáveis econômicas, demográficas e po- 
líticas sobre o gasto público em educação, saúde e seguridade e bemestar social, constatam que os determinantes do gasto em educação e saúde são diferentes dos determinantes do gasto em seguridade e bem-estar social. As variáveis que influenciam positivamente o gasto em educação e saúde são abertura comercial, população com até 16 anos e partidos de esquerda; as que influenciam negativamente, déficit e pontos de veto. Isso quer dizer que, quanto maiores a abertura comercial e a proporção de pessoas em idade escolar, e quanto mais à esquerda do espectro ideológico está o governo, maior o gasto em educação e saúde. Por outro lado, quanto maiores o déficit e a incidência de pontos de veto, menor o gasto naquelas áreas. Já os determinantes do gasto em seguridade e bem-estar social são população com mais de 65 anos, governos de direita e déficit público; as duas primeiras variáveis influenciando positivamente e a última negativamente. Ou seja, quanto maior a proporção de pessoas com mais de 65 anos e quanto mais à direita do espectro ideológico está o governo, maior o gasto em seguridade e bem-estar social, ao passo que, quanto maior o déficit, menor o gasto nessas áreas.

Outra variável fundamental para entendermos o processo de formulação de políticas públicas na América Latina, em função do sistema presidencialista, é a variável natureza do governo. Ou seja, a composição partidária do Executivo no Legislativo. Vejamos o porquê dessa afirmação na seção seguinte.

\section{A Importância da Natureza do Governo para a Análise da América Latina}

Grande parte dos estudos sobre a relação entre partidos e políticas públicas tem como referência as democracias parlamentaristas da Europa, nas quais encontramos partidos disciplinados, governo dependente da confiança parlamentar e aprovação de agenda governamental como condições para a continuidade do partido ou a coalizão do partido no poder. A análise para a América Latina, entretanto, não deve deixar de considerar as especificidades do sistema presidencialista predominante na região, altamente fragmentado em alguns países e, por conseqüência, com maiores dificuldades em formar maioria no Congresso Nacional, o que, teoricamente, dificulta a aprovação de políticas públicas em virtude da ampliação dos pontos de veto. Seguindo esse raciocínio, a eficiência nos governos presidencialistas latino-americanos seria prejudicada pela maior dificuldade em obtenção de apoio 
partidário para aprovação de políticas públicas, preservando, no limite, o status quo.

A análise das políticas públicas dos países da América Latina deve considerar não só os partidos que apóiam o Executivo mas também a composição partidária dominante no Legislativo (Alesina e Rosenthal, 1995). Disso decorre que a relação entre partido político e políticas públicas só pode ser entendida nessa região quando se acrescenta à explicação a possibilidade de ocorrência de governos divididos, ou seja, um Executivo apoiado por tendências ideológicas distintas da tendência ideológica dos partidos majoritários no Legislativo ${ }^{3}$. É natural imaginar que, quando Executivo e Legislativo são dominados por tendências ideológicas conflitantes, a variação nas políticas públicas é menor do que quando os partidos que apóiam o governo e dominam o Legislativo convergem para a mesma tendência programática (Tsebelis, 1995).

Tendo como base a contribuição de Mejía Acosta e Coppedge (2001), cuja eficiência foi comprovada e adotada por Amorim Neto e Borsani (2004), de acordo com a qual o efeito de determinadas variáveis políticas sobre políticas públicas é potencializado quando algumas dessas variáveis são interagidas, duas variáveis políticas de grande relevância para os objetivos deste estudo serão interagidas. São elas: ideologia do governo e força legislativa do governo. A intenção é observar se, em mandatos nos quais encontramos governos de esquerda com maioria parlamentar, os gastos em educação e saúde são mais elevados do que nos demais governos, sobretudo naqueles de direita ${ }^{4}$. A elaboração das hipóteses de trabalho e a metodologia utilizada para análise das políticas públicas nos países da América Latina, assim como a descrição das variáveis incorporadas aos modelos estatísticos, todas elas inspiradas na literatura pertinente vista nos parágrafos anteriores, serão tratadas na seção seguinte.

\section{MODELO ESTATÍSTICO E TESTES ECONOMÉTRICOS}

Com base na teoria segundo a qual governos de esquerda buscam um perfil mais universalista e redistributivo para suas políticas, enquanto governos de direita se preocupam mais com a estabilidade econômica via redução da inflação, a proposição que norteia a hipótese principal deste estudo é: quanto mais à esquerda do espectro ideológico está o governo, maior o nível do gasto em educação e saúde ${ }^{5}$. Contudo, sendo o sistema de 
governo predominante na América Latina o presidencialista, faz-se necessário incluir na análise não só a inclinação ideológica do Executivo, mas também sua composição no Legislativo. Os sistemas partidários latino-americanos são, em alguns países da região, altamente fragmentados, o que exige a formação de coalizões para garantir a governabilidade. Assim, espera-se que, quanto maior a correlação de forças do governo no Legislativo, menores os pagamentos colaterais a serem distribuídos para a formação de maiorias que apóiem as propostas do Executivo, facilitando a implementação de políticas públicas (Alesina e Rosenthal, 1995; Fiorina, 1996; Tsebelis, 1995) ${ }^{6}$.

Diante de tal suposição e com base nos estudos de Mejía Acosta e Coppedge (2001) e Amorim Neto e Borsani (2004), segundo os quais alguns indicadores têm impacto nas políticas públicas de forma interativa, e não linear, proponho a seguinte hipótese de trabalho: o nível do gasto em educação e saúde é maior em governos de esquerda majoritários em comparação a governos de direita (divididos ou unificados).

A expectativa é que o gasto social seja maior em governos de esquerda majoritários, porque, com base na teoria vista nas seções anteriores, governos que contam com maioria legislativa encontram mais facilidade em implementar uma agenda de políticas que, espera-se, seja condizente com seu perfil ideológico do que governos minoritários, nos quais negociações e acordos colaterais se fazem necessários. Dada a necessidade de busca permanente de apoio, governos minoritários precisam negociar constantemente com partidos ideologicamente mais afastados e, muitas vezes, em troca desse apoio político, aprovar políticas de menor identidade ideológica.

No intuito de avaliar a influência das variáveis políticas sobre os gastos sociais dos países latino-americanos durante o período compreendido entre 1980 e 1999, proponho um modelo de análise que inclui variáveis relacionadas à ideologia do governo (governos de esquerda, de centro e de direita ${ }^{7}$ ) e à sua composição legislativa (governos majoritário, de esquerda majoritário e de centro majoritário). As variáveis socioeconômicas (população urbana, dependência demográfica ${ }^{8}$, Produto Interno Bruto - PIB per capita, inflação, desemprego, abertura comercial e gasto público total - GPT) serão incluídas como controle nos modelos. Veja a especificação do Modelo 1 a seguir: 


\section{Modelo 1}

$\mathrm{GS}_{\mathrm{i}, \mathrm{t}}=b_{0}+b_{1} \operatorname{lgPIB}_{\mathrm{it}}+b_{2} \operatorname{lgInfla}_{\mathrm{it}}+b_{3}$ Des $_{\mathrm{it}}+b_{4}$ PPPbas $_{\mathrm{it}}+b_{5}$ Expend $_{\mathrm{it}}+$ $b_{6}$ Depdemo $_{\mathrm{it}}+b_{7}$ PopUrb $_{\mathrm{it}}+b_{8}$ Esq $_{\mathrm{it}}+b_{9}$ Cen $_{\mathrm{it}}+b_{10}$ Gabuni $_{\mathrm{it}}+$ $b_{11}$ EsqxGabuni $_{\text {it }}+b_{12}$ CenxGabuni $_{\text {it }}$

Em que:

GS = gasto em educação e saúde como \% do PIB e como \% do gasto público total.

$\lg P I B=$ PIB per capita em sua função logarítmica do país $i$ no ano $t$.

$\lg$ Infla = variação anual da inflação em sua função logarítmica do país $i$ no ano $t$.

Des $=$ variação do desemprego em proporção da força de trabalho total do país $i$ no ano $t$.

PPPbas $=$ exportação + importação / PPP no país $i$ no ano $t$.

Expend $=$ gasto total em relação ao PIB do país $i$ no ano $t$.

Depdemo $=\%$ de dependentes sobre a população economicamente ativa do país $i$ no ano $t$.

PopUrb $=\%$ da população urbana do país $i$ no ano $t$.

$E s q=$ dummy para governos de esquerda.

Cen $=$ dummy para governos de centro.

Gabuni = dummy para governos com maioria legislativa.

EsqxGabuni $=$ produto das variáveis Esq e Gabuni.

CenxGabuni $=$ produto das variáveis Cen e Gabuni.

$\mathrm{i}=$ países $(1,2,3, \ldots, 14)$.

$\mathrm{t}=1980,1988,1989, \ldots, 1999$.

A variável a ser explicada, gasto social $(G S)^{9}$, diz respeito à soma das porcentagens do gasto em educação e saúde tanto como porcentagem do gasto público total quanto como porcentagem do PIB. Assim, o modelo econométrico será estimado duas vezes, uma utilizando o primeiro indicador de gasto social (em proporção ao gasto público total) e outra o segundo indicador de gasto social (em proporção ao PIB do país).

Buscando o melhor aproveitamento das análises dos dados estatísticos, proponho desagregar o gasto social em educação e saúde, novamente como porcentagem do gasto público total e como porcentagem do PIB, e reestimar os modelos. Esse procedimento vai gerar um resultado final de seis conjuntos de estimativa. Ou seja, o primeiro modelo a ser estimado terá como variável dependente a soma do gasto em educação e saúde como porcentagem do gasto público total; no segundo 
modelo, a variável dependente corresponderá à soma do gasto em educação e saúde como porcentagem do PIB; no terceiro e no quarto modelos, ao gasto em educação como porcentagem do gasto público total e como porcentagem do PIB, respectivamente; no quinto e no sexto, ao gasto em saúde como porcentagem do gasto público total e como porcentagem do PIB.

Não é meu objetivo neste artigo definir de antemão o melhor indicador de gasto social, se agregado, se desagregado, se como porcentagem do PIB ou se em proporção ao gasto público total. Na literatura que analisa o gasto público social, observam-se pequenas alterações nos resultados dependendo do indicador utilizado. Em Kaufman e Segura-Ubiergo (2001), por exemplo, vemos que cada uma das três categorias de gasto social - agregado, educação e saúde - é influenciada por diferentes conjuntos de fatores políticos e econômicos. Em Avelino, Brown e Hunter (2005), também podemos encontrar diferença nos resultados quando os dados são tratados de forma agregada e quando são tratados de forma desagregada.

As variáveis de controle de natureza econômica incluídas nos modelos econométricos são: PIB per capita em sua forma logarítmica $(\lg P I B)^{10}$; inflação, também em sua forma logarítmica $(\lg I n f l a)^{11}$; desemprego $(\text { Des })^{12}$; abertura comercial (PPPbas $)^{13}$; e gasto público total (Expend $)^{14}$. A variável referente à abertura comercial foi incluída no modelo para permitir a verificação do efeito da globalização no gasto social.

Já as variáveis de controle de natureza demográfica são: dependência demográfica (Depdemo $)^{15}$, que representa a porcentagem de dependentes (população idosa e população em idade escolar) sobre a população economicamente ativa; e população urbana $(P o p U r b)^{16}$. De acordo com Huber, Mustillo e Stephens (2004), a população em idade escolar influencia positivamente o gasto em educação/saúde, e a população com mais de 65 anos tem impacto positivo sobre seguridade/bem-estar social.

Finalmente, as variáveis explicativas de natureza política, fundamentais para o teste de hipótese do trabalho, são: esquerda (Esq), que assume valor 1 quando o governo é de esquerda e 0 , caso contrário; centro (Cen), que assume valor 1 quando o governo é de centro e 0 , caso contrário; natureza do governo (Gabuni) ${ }^{17}$, que assume valor 1 quando o gabinete do Executivo é majoritário na Câmara dos Deputados e 0 quando é minoritário; esquerda unificada (EsqxGabuni), uma interação das variáveis "esquerda" e "natureza do governo"; e centro unificado (CenxGabuni), uma interação das variáveis "centro" e "natureza 
do governo"18. Os indicadores de ideologia do governo tiveram como base a classificação de Michael Coppedge $(1997)^{19}$, mas foram extraídos da base de dados de Hugo Borsani elaborada para sua publicação de $2003^{20}$. Nesse estudo, Borsani classifica os governos de centro-esquerda como de esquerda e os de centro-direita como de direita, condensando assim as cinco classificações de Coppedge (1997) (direita, centro-direita, centro, centro-esquerda e esquerda) em três (esquerda, centro e direita). A inclusão dessas variáveis permite testar a hipótese de trabalho segundo a qual governos de esquerda majoritários investem mais no social do que os demais governos. A variável Gabuni, por exclusão de todas as demais combinações de ideologia e de natureza do governo - governos de esquerda minoritário, de centro minoritário, de direita minoritário (base comparativa), de esquerda majoritário e de centro majoritário -, representa a variável correspondente a governo de direita majoritário.

Os sinais esperados para os coeficientes das variáveis explicativas encontram-se no Quadro 1 a seguir:

Quadro 1

Sinais dos Coeficientes das Variáveis Explicativas

\begin{tabular}{|l|c|}
\hline Variável Explicativa & Sinal Esperado \\
\hline lgPIB & + \\
\hline lgInfla & - \\
\hline Des & + \\
\hline PPPbas & $?$ \\
\hline Expend & + \\
\hline Depdemo & + \\
\hline PopUrb & + \\
\hline Esq & + \\
\hline Cen & + \\
\hline Gabuni & - \\
\hline EsqxGabuni & + \\
\hline CenxGabuni & + \\
\hline
\end{tabular}

Elaboração da autora.

Para teste de robustez, um segundo modelo (Modelo 2) será estimado, o que também vai gerar um resultado final de seis conjuntos de estimativa - gasto social agregado (educação + saúde), em educação e em saúde, tanto com relação ao gasto público total quanto com relação ao PIB. 
Nesse modelo, serão excluídas as variáveis que não apresentaram significância estatística no Modelo 1. Além disso, será incluída a variável referente à estabilidade ministerial (Gabestab). O objetivo da inclusão dessa variável é verificar como se comporta o gasto social diante de um gabinete ministerial estável ${ }^{21}$. Segundo os achados de Amorim Neto e Borsani (2004), a estabilidade ministerial, entre outros fatores, como governos de direita e presidentes com partidos fortes, é mais propensa a reduzir o gasto público e promover equilíbrio fiscal. Neste artigo, o objetivo é verificar os efeitos de variáveis políticas sobre o gasto social especificamente, e não sobre o gasto público em geral. Assim, o sinal negativo esperado por Amorim Neto e Borsani (ibidem) para a variável, no caso da análise do gasto público e do déficit fiscal, pode, para a análise do gasto social, ser alterado.

A metodologia adotada no presente estudo para teste de hipótese é a análise econométrica de painel, também conhecida como séries agregadas $^{22}$. Esse tipo de análise permite considerar concomitantemente as dimensões espaço (país) e tempo (ano ${ }^{23}$. Graças à utilização conjunta entre informação temporal e unidades individuais, os problemas de correlação de variáveis omitidas com as explicativas são menores do que aqueles encontrados em bases de dados apenas temporais, também chamadas de time series. Seguindo a sugestão de Beck e Katz (1995), o modelo se baseia em uma estrutura auto-regressiva comum para todos os países (fixed effects), em contraposição a uma estrutura diferente para cada um (random effects). De acordo com os autores, a superioridade desse tipo de modelagem está no fato de, dessa forma, ser possível capturar o efeito das especificidades de cada unidade de análise eventualmente omitidas no modelo, mas que podem estar relacionadas às variáveis explicativas.

Na estimativa dos parâmetros do modelo, seguiu-se o método panel corrected standard error (OLS com erro padrão corrigido), sugerido por Beck e Katz (ibidem) para análises de painel de dimensões similares às deste artigo. Uma discussão presente na literatura refere-se à utilização do lag da variável dependente (ibidem; Achen, 2000; Wawro, 2002). Enquanto Beck e Katz (1995) defendem que a inclusão de valores defasados da variável dependente contribui para o controle de problemas de autocorrelação ${ }^{24}$, Achen (2000) e Wawro (2002) são contrários a esse procedimento. Achen argumenta que a auto-regressividade distorce os resultados na medida em que superdimensiona o poder explicativo 
da variável, ofuscando os efeitos de outras variáveis explicativas e/ou provocando inversão de sinais.

O debate técnico sobre qual é a melhor forma de especificação do modelo não está esgotado. Cabe aos adeptos da econometria optar por um deles. Para efeito deste artigo, será adotada a segunda posição, ou seja, a de não inclusão de valores defasados da variável dependente no modelo. Entendo que tal recurso é pertinente quando o modelo não prevê eventual correlação serial dos dados. No entanto, neste artigo, para dissipar tal problema, utilizo como recurso estatístico a correlação auto-regressiva de primeira ordem - AR1, que também pressupõe uma autocorrelação comum a todos os países. Penso que o uso concomitante do valor defasado da variável dependente e da correlação AR1 é redundante, uma vez que ambos procuram dar conta do mesmo problema: correlação serial ${ }^{25}$.

Os primeiros resultados referentes aos modelos que associam gasto social com as demais variáveis independentes - econômicas, demográficas e políticas - podem ser vistos na Tabela 1.

Os resultados da regressão do Modelo 1, cujo poder preditivo é de $97 \%$ ( $\mathrm{R}^{2}$ ajustado), expostos na Tabela 1 (gasto social como porcentagem do gasto público total), revelam que, entre as variáveis socioeconômicas, aquelas que apresentaram relevância estatística e sinais positivos, conforme previsto, foram: dependência demográfica (Depdemo) e população urbana (PopUrb), ambas no nível de significância de 1\%. Isso quer dizer que, quanto maiores os níveis da dependência demográfica e da população urbana, maior o gasto social. Com relação às variáveis políticas, observou-se que aquelas referentes a governos de esquerda e de centro minoritários ( $E s q$ e Cen) e aquela referente à natureza do governo (Gabuni) apresentaram um nível de significância estatística de 5\% (com exceção da variável referente a governos de centro minoritários, cujo nível de significância estatística foi de 10\%) e sinais negativos. Isso quer dizer que o nível do gasto social tende a diminuir em governos de esquerda e de centro minoritários e também em governos de direita majoritários (lembrando que, por exclusão de todas as demais combinações de ideologia e de natureza do governo, a variável Gabuni representa a variável referente a governo de direita majoritário), se comparados a governos de direita minoritários (categoria de base comparativa). 
Cristiane Batista

Tabela 1

Determinantes do Gasto Social (\% GPT) na América Latina: 1980-1999

\begin{tabular}{|c|c|c|}
\hline Variáveis & $\begin{array}{l}\text { Modelo } \\
\text { (1) }\end{array}$ & $\begin{array}{l}\text { Modelo } \\
\text { (2) }\end{array}$ \\
\hline $\lg P I B$ & $\begin{array}{l}-4,43 \\
(5,36)\end{array}$ & - \\
\hline lgInfla & $\begin{array}{l}-0,27 \\
(0,39)\end{array}$ & - \\
\hline Des & $\begin{array}{c}0,03 \\
(0,17)\end{array}$ & - \\
\hline PPPbas & $\begin{array}{c}5,37 e-13 \\
(1,17 \mathrm{e}-12)\end{array}$ & - \\
\hline Expend_PIB & $\begin{array}{c}0,06 \\
(0,20)\end{array}$ & - \\
\hline Depdemo & $\begin{array}{c}0,78^{* * *} \\
(0,25)\end{array}$ & $\begin{array}{l}0,33^{* *} \\
(0,13)\end{array}$ \\
\hline PopUrb & $\begin{array}{c}1,60 e-06^{* * *} \\
(5,03 e-07)\end{array}$ & $\begin{array}{c}3,47 \mathrm{e}-07^{* * *} \\
(1,32 \mathrm{e}-07)\end{array}$ \\
\hline Esq & $\begin{array}{c}-3,02^{* *} \\
(1,42)\end{array}$ & $\begin{array}{c}-3,03^{* *} \\
(1,52)\end{array}$ \\
\hline Cen & $\begin{array}{l}-5,84^{*} \\
(3,36)\end{array}$ & $\begin{array}{l}-3,57 \\
(2,59)\end{array}$ \\
\hline Gabuni & $\begin{array}{c}-6,02^{* *} \\
(2,75)\end{array}$ & $\begin{array}{c}-4,02^{* *} \\
(2,00)\end{array}$ \\
\hline EsqxGabuni & $\begin{array}{c}10,95^{* * *} \\
(3,21)\end{array}$ & $\begin{array}{c}8,95^{* * *} \\
(2,68)\end{array}$ \\
\hline CenxGabuni & $\begin{array}{l}7,02^{* *} \\
(3,28)\end{array}$ & $\begin{array}{l}5,83^{*} \\
(3,13)\end{array}$ \\
\hline Gabestab & - & $\begin{array}{l}2,92^{*} \\
(1,76)\end{array}$ \\
\hline $\mathrm{R}^{2}$ ajustado & 0,97 & 0,95 \\
\hline $\mathrm{R}^{2}$ (efeitos fixos) & 0,95 & 0,94 \\
\hline $\operatorname{Pr}($ efeitos fixos país $=0)>$ chi $^{2}$ & 0,000 & 0,000 \\
\hline Rho & 0,32 & 0,41 \\
\hline Esq $\mid$ gabuni $=1$ & $\begin{array}{c}7,94^{* * *} \\
(3,05)\end{array}$ & $\begin{array}{l}5,93^{* *} \\
(2,94) \\
\end{array}$ \\
\hline $\mathrm{N}$ & 116 & 130 \\
\hline
\end{tabular}

Erro padrão entre parênteses; ${ }^{*} \mathrm{p}<0,1 ;{ }^{* *} \mathrm{p}<0,05 ;{ }^{* * *} \mathrm{p}<0,01$.

Elaboração da autora. 
Corroborando a hipótese do trabalho, os testes econométricos revelam que, no nível de significância de 1\%, governos de esquerda com maioria legislativa gastam 10,9 pontos percentuais a mais em política social do que governos de direita minoritários. Para verificar quanto do gasto social aumenta em governos de esquerda em comparação a todos os demais governos, somaram-se os coeficientes das variáveis referentes a governo de esquerda dividido ( $E s q)$ e a governo de esquerda unificado $($ Esq $x$ Gabuni). O resultado do teste $(E s q \mid$ gabuni $=1)$ mostra que, no nível de significância estatística de $1 \%$, governos de esquerda majoritários gastam aproximadamente oito pontos percentuais a mais no social do que os demais governos.

O Modelo 2, que exclui as variáveis que não apresentaram significância estatística no Modelo 1 e, além disso, inclui a variável que testa a influência da estabilidade ministerial sobre o gasto social (Gabestab), manteve, em sua maioria, os níveis de significância estatística e os sinais das variáveis presentes no Modelo 1 (o nível de significância estatística da variável correspondente à dependência democrática reduziu de $1 \%$ para 5\%). A variável incluída no Modelo 2 para verificar o efeito da estabilidade ministerial sobre o gasto social (Gabestab) apresentou significância estatística no nível de $10 \%$ e sinal positivo, em dissonância com as previsões de Amorim Neto e Borsani (2004), segundo as quais a estabilidade ministerial tende a contribuir para a redução do gasto público e promover o equilíbrio fiscal. Os autores, entretanto, não fazem predições sobre o efeito de tal variável sobre o gasto social, que constitui a proposta deste artigo.

No Modelo 2, o teste que verificou quanto a mais governos de esquerda investem no social (Esq I gabuni $=1$ ) apresentou significância estatística no nível de 5\%, um pouco menor do que o nível de significância da respectiva variável no Modelo 1 (1\%), e sinal positivo. Nesse caso, os testes revelaram que o gasto social em proporção ao gasto público total é quase seis pontos percentuais maior do que nos demais governos. $\mathrm{O}$ poder preditivo do modelo é de $95 \%$.

Em suma, os resultados dos Modelos 1 e 2 (gasto social agregado como porcentagem do gasto público total) corroboram a hipótese deste artigo, segundo a qual governos de esquerda majoritários gastam mais em política social do que governos de direita, no caso, de direita minoritários. Além disso, indicam que os determinantes do gasto social em proporção ao gasto público total são: dependência demográfica (relação 
direta); população urbana (relação direta); governos de esquerda minoritários (relação inversa); governos de direita unificados (relação inversa); e governos de centro majoritários (relação direta). Dito de outra forma, o gasto social aumenta em governos de esquerda majoritários (um pouco mais do que em governos de centro majoritários) e à proporção que aumentam o grau de dependência demográfica e a população urbana. Por outro lado, diminui em governos de esquerda minoritários e em governos de direita majoritários. A variável referente à abertura comercial, medida pelo PPP, não apresentou significância estatística em nenhum dos dois modelos; porém, o sinal foi positivo, conforme atestado por Avelino, Brown e Hunter (2005).

Vejamos agora, na Tabela 2, os resultados dos testes estatísticos quando se utiliza como indicador de gasto social o gasto agregado (educação + saúde) em proporção ao PIB.

Os resultados da Tabela 2 revelam que, entre as variáveis econômicas, três aparecem como estatisticamente significativas e com sinais de acordo com o previsto. São elas: PIB per capita (lgPIB), no nível de $10 \%$ de significância estatística e sinal positivo - mas apenas no Modelo 1 -; inflação (lgInfla), no nível de $1 \%$ e sinal negativo; e gasto público total (Expend), também no nível de $1 \%$ e sinal positivo. Isso significa que o gasto social aumenta à medida que aumentam o PIB (relação fraca) e o gasto público do país, e diminui de acordo com o aumento da inflação. Entre as variáveis demográficas, a única que apresentou significância estatística e sinal positivo nos dois modelos corresponde à dependência demográfica. Significa dizer que o gasto social aumenta conforme aumenta o nível de dependência demográfica do país. A variável referente à população urbana não apresentou relevância estatística.

Nessa análise, mais uma vez a hipótese de trabalho é comprovada. Os resultados indicam que, no nível de significância estatística de 1\%, governos de esquerda majoritários investem 1,6 ponto percentual a mais no social do que governos de direita minoritários (categoria de base comparativa). O teste que verifica quanto a mais governos de esquerda gastam em política social (Esq I gabuni $=1$ ) apresentou significância estatística, ainda que no nível baixo (10\%), apenas no Modelo 1, mas o sinal foi positivo em ambos os modelos, indicando que o nível do gasto social em governos de esquerda tende a ser 0,8 ponto percentual maior quando comparado aos demais governos. Dessa vez, o nível de significância estatística da variável que mede a influência de governos de di- 
Partidos Políticos, Ideologia e Política Social na América Latina: 1980-1999

Tabela 2

Determinantes do Gasto Social (\% PIB) na América Latina: 1980-1999

\begin{tabular}{|c|c|c|}
\hline Variáveis & $\begin{array}{c}\text { Modelo } \\
\text { (1) }\end{array}$ & $\begin{array}{c}\text { Modelo } \\
\text { (2) }\end{array}$ \\
\hline \multirow[t]{2}{*}{$\lg P I B$} & $1,77^{*}$ & 1,03 \\
\hline & $(0,95)$ & $(0,90)$ \\
\hline \multirow[t]{2}{*}{ lgInfla } & $-0,26^{* * *}$ & $-0,19^{* * *}$ \\
\hline & $(0,84)$ & $(0,07)$ \\
\hline \multirow[t]{2}{*}{ Des } & 0,01 & - \\
\hline & $(0,03)$ & \\
\hline \multirow[t]{2}{*}{ PPPbas } & $8,46 \mathrm{e}-14$ & - \\
\hline & $(1,62 \mathrm{e}-13)$ & \\
\hline \multirow[t]{2}{*}{ Expend } & $2,41 \mathrm{e}-13^{* * *}$ & $2,39 \mathrm{e}-13^{* * *}$ \\
\hline & $(3,77 \mathrm{e}-14)$ & $(3,72 \mathrm{e}-14)$ \\
\hline \multirow[t]{2}{*}{ Depdemo } & $0,23^{* * *}$ & $0,19^{* * *}$ \\
\hline & $(0,04)$ & $(0,03)$ \\
\hline \multirow[t]{2}{*}{ PopUrb } & $2,83 \mathrm{e}-08$ & - \\
\hline & $(9,31 \mathrm{e}-08)$ & \\
\hline \multirow[t]{2}{*}{ Esq } & $-0,70^{* * *}$ & $-0,94^{* * *}$ \\
\hline & $(0,26)$ & $(0,27)$ \\
\hline \multirow[t]{2}{*}{ Cen } & $-1,13^{*}$ & $-0,66$ \\
\hline & $(0,66)$ & $(0,59)$ \\
\hline \multirow[t]{2}{*}{ Gabuni } & $-1,43^{* * *}$ & $-1,02^{* * *}$ \\
\hline & $(0,43)$ & $(0,38)$ \\
\hline \multirow[t]{2}{*}{ EsqxGabuni } & $1,56^{* * *}$ & $1,36^{* * *}$ \\
\hline & $(0,52)$ & $(0,50)$ \\
\hline \multirow[t]{2}{*}{ CenxGabuni } & $1,44^{* *}$ & $1,12^{*}$ \\
\hline & $(0,67)$ & $(0,66)$ \\
\hline \multirow[t]{2}{*}{ Gabestab } & - & $0,52^{*}$ \\
\hline & & $(0,30)$ \\
\hline$R^{2}$ ajustado & 0,98 & 0,98 \\
\hline $\mathrm{R}^{2}$ (efeitos fixos) & 0,92 & 0,92 \\
\hline $\operatorname{Pr}($ efeitos fixos país $=0)>$ chi $^{2}$ & 0,000 & 0,000 \\
\hline Rho & 0,37 & 0,37 \\
\hline \multirow[t]{2}{*}{ Esq $\mid$ gabuni $=1$} & $0,86^{*}$ & 0,42 \\
\hline & $(0,47)$ & $(0,48)$ \\
\hline $\mathrm{N}$ & 116 & 122 \\
\hline
\end{tabular}

Erro padrão entre parênteses; ${ }^{*} \mathrm{p}<0,1 ;{ }^{* *} \mathrm{p}<0,05 ;{ }^{* * *} \mathrm{p}<0,01$.

Elaboração da autora. 
reita majoritários (Gabuni) sobre o gasto social foi mais expressivo, 1\%, além de o sinal ser negativo, indicando que o investimento na área é menor em governos de direita majoritários perante os governos de direita minoritários.

Assim como na análise que utiliza o gasto social como porcentagem do gasto público total (Tabela 1), os resultados revelam que governos de esquerda sem maioria legislativa investem menos em educação e saúde. Uma possível resposta para esse achado é a natural fraqueza política de governos minoritários, o que obviamente afeta sua capacidade de implementação da agenda programática de políticas. Em governos minoritários, o objetivo principal dos partidos de oposição é dificultar a execução do programa do governo em exercício a fim de inviabilizar sua reeleição. Sendo as políticas sociais a prioridade de governos de esquerda (atendendo à linha conceitual defendida neste artigo), é natural que uma maioria de oposição crie obstáculos para a realização de tal programa.

Em suma, os dados expostos na Tabela 2 revelam que as variáveis intervenientes do gasto social em proporção ao PIB são: PIB per capita (relação direta, mas fraca); inflação (relação inversa); gasto público total (relação direta); dependência demográfica (relação direta); governos de esquerda minoritários (relação inversa); governos de centro minoritários (relação inversa e fraca); governos de direita majoritários (relação inversa); governos de esquerda majoritários (relação direta); e governos de centro majoritários (relação direta, mas relativamente fraca). Novamente a variável que verifica o efeito da estabilidade ministerial sobre o gasto social (Gabestab) apresentou sinal positivo e significância estatística, ainda que em um nível baixo, $10 \%$.

Nas Tabelas 1 e 2, vimos como o gasto social agregado, tanto como porcentagem do gasto público total quanto como porcentagem do PIB, se comporta na presença de variáveis políticas e socioeconômicas. Vejamos agora o comportamento do gasto social ao desagregarmos o gasto em educação e saúde em proporção ao gasto público total.

Os resultados da Tabela 3, que apresenta a análise do gasto em educação como porcentagem do gasto público total, revelam que, assim como na análise do gasto social agregado, que tem como parâmetro também o gasto público total, entre as variáveis socioeconômicas, apenas as variáveis referentes à dependência demográfica e à população urbana revelaram-se estatisticamente significativas: a primeira no ní- 
Partidos Políticos, Ideologia e Política Social na América Latina: 1980-1999

Tabela 3

Determinantes do Gasto em Educação (\% GPT) na América Latina: 1980-1999

\begin{tabular}{|c|c|c|}
\hline Variáveis & $\begin{array}{c}\text { Modelo } \\
\text { (1) }\end{array}$ & $\begin{array}{c}\text { Modelo } \\
\text { (2) }\end{array}$ \\
\hline \multirow[t]{2}{*}{$\lg P I B$} & $-1,32$ & - \\
\hline & $(2,99)$ & \\
\hline \multirow[t]{2}{*}{ lgInfla } & $-0,29$ & - \\
\hline & $(0,19)$ & \\
\hline \multirow[t]{2}{*}{ Des } & 0,03 & - \\
\hline & $(0,09)$ & \\
\hline \multirow[t]{2}{*}{ PPPbas } & $1,01 \mathrm{e}-13$ & - \\
\hline & $(5,37 \mathrm{e}-13)$ & \\
\hline \multirow[t]{2}{*}{ Expend_PIB } & 0,00 & - \\
\hline & $(0,10)$ & \\
\hline \multirow[t]{2}{*}{ Depdemo } & $0,36^{* * *}$ & $0,25^{* * *}$ \\
\hline & $(0,12)$ & $(0,08)$ \\
\hline \multirow[t]{2}{*}{ PopUrb } & $4,48 \mathrm{e}-07^{*}$ & $1,67 \mathrm{e}-07^{* * *}$ \\
\hline & $(2,49 \mathrm{e}-07)$ & $(5,07 e-08)$ \\
\hline \multirow[t]{2}{*}{ Esq } & $-0,75$ & $-1,14$ \\
\hline & $(0,76)$ & $(0,78)$ \\
\hline \multirow[t]{2}{*}{ Cen } & $-1,68$ & - \\
\hline & $(1,55)$ & \\
\hline \multirow[t]{2}{*}{ Gabuni } & $-2,03$ & $-0,60$ \\
\hline & $(1,25)$ & $(0,54)$ \\
\hline \multirow[t]{2}{*}{ EsqxGabuni } & $3,42^{* *}$ & $2,68^{* * *}$ \\
\hline & $(1,46)$ & $(1,00)$ \\
\hline \multirow[t]{2}{*}{ CenxGabuni } & 2,37 & - \\
\hline & $(1,52)$ & \\
\hline \multirow[t]{2}{*}{ Gabestab } & - & 1,15 \\
\hline & & $(0,77)$ \\
\hline$R^{2}$ ajustado & 0,97 & 0,96 \\
\hline$R^{2}$ (efeitos fixos) & 0,94 & 0,94 \\
\hline $\operatorname{Pr}($ efeitos fixos país $=0)>$ chi $^{2}$ & 0,000 & 0,000 \\
\hline Rho & 0,34 & 0,41 \\
\hline \multirow[t]{2}{*}{ Esq $\mid$ gabuni $=1$} & $2,68^{* *}$ & 1,54 \\
\hline & $(1,32)$ & $(1,08)$ \\
\hline $\mathrm{N}$ & 116 & 130 \\
\hline
\end{tabular}

Erro padrão entre parênteses; * $\mathrm{p}<0,1 ;{ }^{* *} \mathrm{p}<0,05 ;{ }^{* * *} \mathrm{p}<0,01$.

Elaboração da autora. 
vel de $1 \%$ nos dois modelos; a segunda, $10 \%$ no Modelo 1 e $1 \%$ no Modelo 2, mantendo sempre o sinal positivo. Ou seja, os resultados da Tabela 3 confirmam os achados das Tabelas 1 e 2, segundo os quais quanto maior a dependência demográfica do país, maior seu nível de gasto social, nesse caso específico, de gasto em educação.

Entre as variáveis políticas, apenas a variável referente a governos de esquerda majoritários apresentou-se estatisticamente significativa, no nível de $5 \%$ no Modelo 1 e de $1 \%$ no Modelo 2 . O resultado mostra que governos de esquerda com maioria legislativa gastam aproximadamente três pontos percentuais a mais em educação do que governos de direita minoritários, o que corrobora mais uma vez a hipótese defendida neste artigo. Nesse modelo, nenhuma variável econômica se revelou estatisticamente significativa.

O teste que verifica quanto a mais governos de esquerda gastam em política social (Esq I gabuni $=1$ ) apresentou significância estatística, de 5\%, apenas no Modelo 1 e manteve o sinal positivo, revelando que esses governos investem aproximadamente três pontos percentuais a mais na área do que os demais governos.

Em síntese, de acordo com os resultados alcançados, expostos na Tabela 3, as variáveis que exercem influência sobre o gasto em educação como porcentagem do gasto público total são: dependência demográfica (relação direta); população urbana (relação direta); e governos de esquerda majoritários (relação direta). Dessa vez, a variável Gabestab não apresentou significância estatística em nenhum nível, mas o sinal permaneceu positivo.

Vejamos, na Tabela 4, como se comporta o gasto em educação em relação ao PIB.

Os resultados expostos na Tabela 4 revelam que, diferentemente de quando o gasto em educação tem como parâmetro o gasto público total, duas variáveis econômicas apresentam significância estatística no nível de 1\%: inflação (em sua forma logarítmica) e gasto público total. Ou seja, os testes econométricos revelam que o gasto em educação em proporção ao PIB tende a diminuir conforme aumenta a inflação e a crescer de acordo com o aumento do gasto público total. Entre as variáveis demográficas, apenas a variável referente ao nível de dependência demográfica apresentou significância estatística (1\%) e sinal positivo, tanto no Modelo 1 quanto no Modelo 2. Os resultados da Tabela 4 
Partidos Políticos, Ideologia e Política Social na América Latina: 1980-1999

Tabela 4

Determinantes do Gasto em Educação (\% PIB) na América Latina: 1980-1999

\begin{tabular}{|c|c|c|}
\hline Variáveis & $\begin{array}{c}\text { Modelo } \\
\text { (1) }\end{array}$ & $\begin{array}{c}\text { Modelo } \\
\text { (2) }\end{array}$ \\
\hline $\lg P I B$ & $\begin{array}{c}0,93 \\
(0,62)\end{array}$ & - \\
\hline lgInfla & $\begin{array}{c}-0,19^{* * *} \\
(0,05)\end{array}$ & $\begin{array}{c}-0,17^{* * *} \\
(0,04)\end{array}$ \\
\hline Des & $\begin{array}{c}0,00 \\
(0,02)\end{array}$ & - \\
\hline PPPbas & $\begin{array}{c}-5,05 e-14 \\
(8,47 e-14)\end{array}$ & - \\
\hline Expend & $\begin{array}{c}1,19 \mathrm{e}-13^{* * *} \\
(2,88 \mathrm{e}-14)\end{array}$ & $\begin{array}{c}1,02 e-13^{* * *} \\
(2,27 e-14)\end{array}$ \\
\hline Depdemo & $\begin{array}{c}0,11^{* * *} \\
(0,03)\end{array}$ & $\begin{array}{c}0,11^{* * *} \\
(0,02)\end{array}$ \\
\hline PopUrb & $\begin{array}{c}-6,38 \mathrm{e}-08 \\
(6,13 e-08)\end{array}$ & - \\
\hline Esq & $\begin{array}{c}-0,36^{* *} \\
(0,18)\end{array}$ & $\begin{array}{c}-0,60^{* * *} \\
(0,20)\end{array}$ \\
\hline Cen & $\begin{array}{l}-0,50 \\
(0,41)\end{array}$ & $\begin{array}{l}-0,25 \\
(0,36)\end{array}$ \\
\hline Gabuni & $\begin{array}{c}-0,69^{* * *} \\
(0,21)\end{array}$ & $\begin{array}{c}-0,49 * * * \\
(0,19)\end{array}$ \\
\hline EsqxGabuni & $\begin{array}{l}0,58^{* *} \\
(0,29)\end{array}$ & $\begin{array}{l}0,60^{* *} \\
(0,30)\end{array}$ \\
\hline CenxGabuni & $\begin{array}{l}0,71^{*} \\
(0,40)\end{array}$ & $\begin{array}{c}0,56 \\
(0,39)\end{array}$ \\
\hline Gabestab & - & $\begin{array}{c}0,12 \\
(0,17) \\
\end{array}$ \\
\hline $\mathrm{R}^{2}$ ajustado & 0,97 & 0,97 \\
\hline$R^{2}$ (efeitos fixos) & 0,90 & 0,90 \\
\hline $\operatorname{Pr}($ efeitos fixos país $=0)>$ chi $^{2}$ & 0,000 & 0,000 \\
\hline Rho & 0,44 & 0,43 \\
\hline Esq $\mid$ gabuni $=1$ & $\begin{array}{c}0,22 \\
(0,22)\end{array}$ & $\begin{array}{l}-0,00 \\
(0,25)\end{array}$ \\
\hline $\mathrm{N}$ & 116 & 122 \\
\hline
\end{tabular}

Erro padrão entre parênteses; ${ }^{*} \mathrm{p}<0,1 ;{ }^{* *} \mathrm{p}<0,05 ;{ }^{* * *} \mathrm{p}<0,01$.

Elaboração da autora. 
confirmam, portanto, os achados das tabelas anteriores, segundo os quais quanto maior a dependência demográfica do país, maior o gasto em educação. A variável referente à população urbana não apresentou significância estatística.

Mais uma vez a hipótese deste estudo é corroborada. Os resultados mostram que, no nível de significância estatística de $5 \%$, governos de esquerda majoritários (Gabuni) investem aproximadamente 0,6 ponto percentual a mais em educação do que governos de direita minoritários. Por sua vez, o teste que verifica quanto a mais governos de esquerda gastam em política social (Esq I gabuni $=1$ ) em relação a todos os demais governos não apresentou significância estatística em nenhum dos dois modelos, tendo apresentado ainda sinal negativo no Modelo 2.

Sumarizando, no que diz respeito ao gasto em educação como porcentagem do PIB, as variáveis intervenientes são: inflação (relação inversa); gasto público total (relação direta); dependência demográfica (relação direta); governos de esquerda minoritários (relação inversa); governos de direita majoritários, testados pela variável Gabuni (relação inversa); e governos de esquerda majoritários (relação direta). Assim como na análise do gasto em educação como porcentagem do gasto público total (Tabela 3), a variável referente à estabilidade do gabinete (Gabestab), incluída em teste de robustez apenas no Modelo 2, não apresentou significância estatística em nenhum nível. O sinal da variável, porém, manteve-se positivo.

Quanto ao gasto público em saúde, tanto como porcentagem do gasto público total quanto como porcentagem do PIB, os resultados podem ser vistos, respectivamente, nas Tabelas 5 e 6.

Os resultados da análise do gasto em saúde em relação ao gasto público total, expostos na Tabela 5, revelam que, assim como na análise do gasto em educação como porcentagem do gasto público total, nenhuma variável econômica apresentou significância estatística; porém, ao contrário da tabela anterior, manteve o sinal positivo da variável referente à abertura comercial (PPPbas). Entre as variáveis demográficas, ambas mostraram-se relevantes e com sinais positivos, mas apenas no Modelo 1. A primeira variável demográfica (Depdemo) apresenta-se estatisticamente significativa no nível de $5 \%$; a segunda (PopUrb), no nível de $1 \%$. Tais resultados permitem concluir que o gasto em saúde, quando ponderado pelo gasto público total, aumenta de acordo com os níveis de dependência demográfica e da população urbana. 
Partidos Políticos, Ideologia e Política Social na América Latina: 1980-1999

Tabela 5

Determinantes do Gasto em Saúde (\% GPT) na América Latina: 1980-1999

\begin{tabular}{|c|c|c|}
\hline Variáveis & $\begin{array}{c}\text { Modelo } \\
\text { (1) }\end{array}$ & $\begin{array}{c}\text { Modelo } \\
(2)\end{array}$ \\
\hline \multirow[t]{2}{*}{$\lg P I B$} & $-3,13$ & - \\
\hline & $(3,18)$ & \\
\hline \multirow[t]{2}{*}{ lgInfla } & $-0,07$ & - \\
\hline & $(0,22)$ & \\
\hline \multirow[t]{2}{*}{ Des } & $-0,01$ & - \\
\hline & $(0,09)$ & \\
\hline \multirow[t]{2}{*}{ PPPbas } & $2,95 \mathrm{e}-13$ & - \\
\hline & $(5,75 e-13)$ & \\
\hline \multirow[t]{2}{*}{ Expend_PIB } & 0,02 & - \\
\hline & $(0,13)$ & \\
\hline \multirow[t]{2}{*}{ Depdemo } & $0,34^{* *}$ & 0,04 \\
\hline & $(0,18)$ & $(0,11)$ \\
\hline \multirow[t]{2}{*}{ PopUrb } & $9,93 \mathrm{e}-07^{* * *}$ & $1,31 \mathrm{e}-07$ \\
\hline & $(3,34 \mathrm{e}-07)$ & $(1,15 e-07)$ \\
\hline \multirow[t]{2}{*}{ Esq } & $-1,94^{* *}$ & $-1,51$ \\
\hline & $(0,88)$ & $(0,96)$ \\
\hline \multirow[t]{2}{*}{ Cen } & $-3,13$ & $-1,44$ \\
\hline & $(2,22)$ & $(1,91)$ \\
\hline \multirow[t]{2}{*}{ Gabuni } & $-3,07^{*}$ & $-1,39$ \\
\hline & $(1,73)$ & $(1,43)$ \\
\hline \multirow[t]{2}{*}{ EsqxGabuni } & $5,82^{* * *}$ & $3,54^{* *}$ \\
\hline & $(2,01)$ & $(1,68)$ \\
\hline \multirow[t]{2}{*}{ CenxGabuni } & $3,69^{*}$ & 2,28 \\
\hline & $(2,16)$ & $(2,28)$ \\
\hline \multirow[t]{2}{*}{ Gabestab } & - & $1,78^{*}$ \\
\hline & & $(1,00)$ \\
\hline $\mathrm{R}^{2}$ ajustado & 0,92 & 0,88 \\
\hline$R^{2}$ (efeitos fixos) & 0,88 & 0,88 \\
\hline $\operatorname{Pr}\left(\right.$ efeitos fixos país $=0$ ) $>$ chi $^{2}$ & 0,000 & 0,000 \\
\hline Rho & 0,45 & 0,57 \\
\hline \multirow[t]{2}{*}{ Esq $\mid$ gabuni $=1$} & $3,88^{* *}$ & 2,03 \\
\hline & $(1,97)$ & $(1,88)$ \\
\hline $\mathrm{N}$ & 116 & 130 \\
\hline
\end{tabular}

Erro padrão entre parênteses; ${ }^{*} \mathrm{p}<0,1 ;{ }^{* *} \mathrm{p}<0,05 ;{ }^{* * *} \mathrm{p}<0,01$.

Elaboração da autora. 
Mais uma vez a hipótese deste estudo foi corroborada. Os resultados revelam que, no nível de significância estatística de 1\%, no Modelo 1, e de 5\%, no Modelo 2, o gasto em saúde como porcentagem do gasto público total é maior em governos de esquerda majoritários. A variável referente à estabilidade ministerial (Gabestab), assim como nos modelos que utilizaram como indicador de gasto social o gasto em educação e saúde (gasto agregado) como porcentagem do gasto público total e como porcentagem do PIB, apresentou nível de significância de $10 \%$ e sinal positivo. Isso quer dizer que o gasto social agregado e o gasto em saúde em proporção ao gasto público total, especificamente, tendem a aumentar quanto maior for a estabilidade do gabinete presidencial. Nos testes realizados por Amorim Neto e Borsani (2004), o sinal da variável foi negativo. No entanto, a variável dependente não era gasto social, mas gasto público.

O resultado do teste realizado para verificar quanto a mais governos de esquerda gastam em política social (Esq I gabuni $=1$ ) apresentou significância estatística de $10 \%$ e sinal positivo esperado, mas apenas no Modelo 1. Cabe lembrar que esse teste soma os coeficientes das variáveis referentes a governos de esquerda minoritários e a governos de esquerda majoritários, ou seja, mostra quanto a mais governos de inclinação ideológica de esquerda investem, nesse caso específico, em política de saúde. O resultado desse teste, para a estimativa expressa no Modelo 1, da Tabela 5, mostra que o gasto em saúde em proporção ao gasto público total aumenta aproximadamente quatro pontos percentuais em governos de esquerda.

Em síntese, as variáveis que exercem influência sobre o gasto em saúde como porcentagem do gasto público total são: dependência demográfica (relação direta, ainda que fraca e apenas no Modelo 1); população urbana (relação direta, mas também somente no Modelo 1); governos de esquerda minoritários (relação inversa, somente no Modelo 1); governos de esquerda majoritários (relação direta); governos de centro majoritários (relação direta, mas fraca e apenas no Modelo 1); e estabilidade ministerial (relação direta), no nível de significância estatística de $10 \%$.

Por último, vejamos, na Tabela 6, como se comporta o gasto em saúde quando ponderado pelo PIB nacional.

As estimativas dos Modelos 1 e 2, expressas na Tabela 6 (gasto em saúde como porcentagem do PIB), revelam que, diferentemente das esti- 
Partidos Políticos, Ideologia e Política Social na América Latina: 1980-1999

Tabela 6

Determinantes do Gasto em Saúde (\% PIB) na América Latina: 1980-1999

\begin{tabular}{|c|c|c|}
\hline Variáveis & $\begin{array}{c}\text { Modelo } \\
\text { (1) }\end{array}$ & $\begin{array}{c}\text { Modelo } \\
\text { (2) }\end{array}$ \\
\hline $\lg P I B$ & $\begin{array}{c}0,75 \\
(0,56)\end{array}$ & - \\
\hline lgInfla & $\begin{array}{l}-0,07 \\
(0,04)\end{array}$ & - \\
\hline Des & $\begin{array}{l}-0,01 \\
(0,02)\end{array}$ & - \\
\hline PPPbas & $\begin{array}{c}1,28 \mathrm{e}-13 \\
(9,17 \mathrm{e}-14)\end{array}$ & - \\
\hline Expend & $\begin{array}{c}1,22 \mathrm{e}-13^{* * *} \\
(1,99 \mathrm{e}-14)\end{array}$ & $\begin{array}{c}1,44 \mathrm{e}-13^{* * *} \\
(2,22 \mathrm{e}-14)\end{array}$ \\
\hline Depdemo & $\begin{array}{c}0,11^{* * *} \\
(0,02)\end{array}$ & $\begin{array}{c}0,10^{* * *} \\
(0,02)\end{array}$ \\
\hline PopUrb & $\begin{array}{l}8,83 \mathrm{e}-08^{*} \\
(5,06 \mathrm{e}-08)\end{array}$ & $\begin{array}{l}3,56 \mathrm{e}-08^{*} \\
(2,06 \mathrm{e}-08)\end{array}$ \\
\hline Esq & $\begin{array}{c}-0,31^{* *} \\
(0,14)\end{array}$ & $\begin{array}{c}-0,37^{* *} \\
(0,15)\end{array}$ \\
\hline Cen & $\begin{array}{l}-0,60 \\
(0,42)\end{array}$ & $\begin{array}{l}-0,33 \\
(0,39)\end{array}$ \\
\hline Gabuni & $\begin{array}{c}-0,69^{* *} \\
(0,29)\end{array}$ & $\begin{array}{l}-0,49^{*} \\
(0,26)\end{array}$ \\
\hline EsqxGabuni & $\begin{array}{c}0,91^{* * *} \\
(0,34)\end{array}$ & $\begin{array}{l}0,63^{* *} \\
(0,30)\end{array}$ \\
\hline CenxGabuni & $\begin{array}{l}0,69^{*} \\
(0,41)\end{array}$ & $\begin{array}{c}0,54 \\
(0,45)\end{array}$ \\
\hline Gabuni & - & $\begin{array}{l}0,45^{* *} \\
(0,18)\end{array}$ \\
\hline $\mathrm{R}^{2}$ ajustado & 0,97 & 0,96 \\
\hline $\mathrm{R}^{2}$ (efeitos fixos) & 0,89 & 0,89 \\
\hline $\operatorname{Pr}($ efeitos fixos país $=0)>$ chi $^{2}$ & 0,000 & 0,000 \\
\hline Rho & 0,38 & 0,50 \\
\hline Esq $\mid$ gabuni $=1$ & $\begin{array}{l}0,59 * \\
(0,33)\end{array}$ & $\begin{array}{c}0,26 \\
(0,32) \\
\end{array}$ \\
\hline $\mathrm{N}$ & 116 & 127 \\
\hline
\end{tabular}

Erro padrão entre parênteses; ${ }^{*} \mathrm{p}<0,1 ;{ }^{* *} \mathrm{p}<0,05 ;{ }^{* *} \mathrm{p}<0,01$.

Elaboração da autora. 
mativas que têm como variável dependente o gasto em saúde como porcentagem do gasto público total (Tabela 5), quando nenhuma variável econômica apresentou significância estatística, dessa vez a variável referente ao gasto público total aparece com nível de significância estatística de $1 \%$ nos dois modelos e sinal positivo. Isso significa que o gasto em saúde aumenta de acordo com o aumento do gasto público federal. Mais uma vez a variável referente à abertura comercial ( $P$ PPbas) não revelou significância estatística, ainda que o sinal fosse positivo. Entre as variáveis demográficas, aquelas referentes tanto à dependência demográfica quanto à população urbana aparecem como positivas e significativas nos dois modelos; a primeira no nível de $1 \%$ e a segunda no de $10 \%$.

Nesse teste, novamente a hipótese de trabalho é comprovada. A variável referente a governos de esquerda majoritários mostra-se significativa no nível de $1 \%$ no Modelo 1 e de $5 \%$ no Modelo 2. O sinal continua positivo, mostrando que governos de esquerda com maioria legislativa gastam mais em saúde (em relação ao PIB, no caso) do que governos de direita minoritários (categoria de base comparativa). Por sua vez, os testes indicam que governos de esquerda sem maioria legislativa investem em torno de 0,3 ponto percentual a menos (no nível de significância estatística de 5\%). Com relação à influência da estabilidade ministerial sobre o gasto em saúde, a variável correspondente (Gabestab) apresentou significância estatística no nível de 5\% e sinal positivo, o que significa que, quanto maior a estabilidade do gabinete, maior o gasto na área.

O resultado do teste que verifica quanto a mais governos de esquerda gastam em política social (Esq I gabuni $=1$ ) revelou significância estatística da variável no nível de 10\%, mas apenas no Modelo 1, e sinal positivo, conforme o esperado.

Em suma, as variáveis intervenientes do gasto em saúde como porcentagem do PIB são: gasto público total (relação direta); dependência demográfica (relação direta); população urbana (relação direta), ainda que em nível baixo de significância estatística (10\%); governos de esquerda minoritários (relação inversa); governos de direita majoritários (relação inversa); governos de esquerda majoritários (relação direta); e estabilidade ministerial (relação direta).

Cabe ressaltar que a variável referente a desemprego não se revelou estatisticamente significativa em nenhuma estimativa, ou seja, tal indi- 
cador não apresenta qualquer influência sobre o gasto social, nem agregado, nem desagregado.

\section{CONSIDERAÇÕES FINAIS}

Este artigo teve por objetivo investigar, por meio da análise estatística, se a ideologia dos partidos governativos na América Latina afeta as políticas sociais, em um contexto de globalização sob o qual, segundo a literatura, os Estados nacionais perderiam sua autonomia decisória. A principal hipótese testada nos modelos econométricos afirma que governos de esquerda majoritários investem mais, ceteris paribus, em política social do que os demais governos, sobretudo aqueles de direita. Os principais achados das análises econométricas corroboraram a hipótese principal deste estudo. A análise econométrica mostra ainda que, dependendo do indicador de gasto social utilizado - agregado, desagregado, em relação ao gasto público total e em relação ao PIB -, os resultados podem sofrer alterações sobretudo no que diz respeito a variáveis de natureza econômica.

Como já mencionado em parágrafos anteriores, neste artigo, não houve a intenção de discutir problemas de mensuração da variável dependente. Portanto, não se travou aqui uma discussão mais aprofundada sobre o melhor indicador para gasto social. O presente estudo confirma o que é observado na literatura que analisa o gasto público social, ou seja, pequenas alterações nos resultados dependendo do indicador utilizado.

A principal contribuição deste texto está em revelar, de maneira sistemática e rigorosa, que, em primeiro lugar, a abertura comercial iniciada na América Latina durante a década de 1980 não prejudicou a autonomia dos Estados nacionais da região. Ao contrário, observa-se no período uma grande variação nas políticas públicas, em especial nas políticas sociais dos países. Além disso, os testes mostram que os principais determinantes dessas variações atendem a características domésticas, como a ideologia e o apoio legislativo do governo, e sofrem menos influência de fatores de natureza econômica.

Em segundo lugar, a teoria segundo a qual inexiste uma distinção ideológica entre partidos políticos, em especial na América Latina, por causa de uma série de fatores históricos e institucionais, é contestada neste artigo. As análises estatísticas desenvolvidas aqui mostram que existe diferença programática entre governos de esquerda e de direita e que 
essa diferença é claramente percebida na análise do gasto social. Mais do que isso: dada a alta fragmentação de alguns sistemas partidários latino-americanos, as relações entre o Executivo e o Legislativo alteram os resultados de políticas governamentais. Por exemplo, os dados revelam que o gasto social aumenta em governos de esquerda majoritários, mas diminui em governos de esquerda minoritários. O fato de esses governos não contarem com uma maioria legislativa compromete a execução de um dos principais itens de sua agenda programática.

Cumpre registrar que os testes são referentes a um determinado período da história recente durante o qual muito se contestou a relevância da ideologia dos partidos governativos. Contudo, estimulam a discussão sobre a importância dos partidos políticos no contexto atual de grandes transformações para a América Latina. Nos anos 2000, verifica-se uma profunda modificação no mapa político latino-americano, com eleições de candidatos de inclinação de esquerda e execução de políticas claramente voltadas para a parcela da população menos favorecida. Basta observar o programa Bolsa Família, no Brasil, que garantiu, em grande medida, a reeleição do presidente Luiz Inácio Lula da Silva em 2006, com ampla maioria de votos. Caberá a futuras pesquisas replicar os testes aqui feitos com dados relativos à década atual ${ }^{26}$.

(Recebido para publicação em fevereiro de 2007)

(Versão definitiva em maio de 2008) 


\section{NOTAS}

1. Kaufman e Segura-Ubiergo (2001) não encontraram nenhuma evidência de que a expansão comercial estimula investimentos em saúde e educação, mas, por outro lado, encontraram evidências de que ela reduz os investimentos em seguridade social.

2. Medida em relação ao Produto Interno Bruto-PIB corrente, a abertura comercial tem impacto negativo sobre o gasto social. Contudo, se a medida for por meio do Poder de Compra Partidário (Purchasing Power Parity) - PPP, o impacto é positivo, ainda que não significativo, sobre o gasto social agregado. Ao desagregar os dados de gasto social em saúde, educação e seguridade social, nota-se uma associação positiva e significativa sobre os gastos em educação e seguridade social.

3. Para exemplo dessa linha de análise, ver Fiorina (1996).

4. As categorias relativas a governos de centro (minoritários e majoritários) serão incluídas nos modelos estatísticos para efeito da análise econométrica. Contudo, nenhuma consideração a respeito de tais governos, ou seja, sobre o impacto de governos de centro na variação do gasto social será feita neste artigo, dada a ausência na literatura sobre as prioridades políticas desses governos.

5. Dado que governos são controlados por partidos políticos, quando, no texto, se fala em governos de esquerda, por exemplo, estão relacionados a governos controlados por partidos de esquerda.

6. Na análise para a América Latina, será observada apenas a composição partidária da Câmara dos Deputados nos casos de países bicamerais.

7. Corresponde à categoria de base comparativa.

8. Porcentagem de dependentes sobre a população economicamente ativa.

9. Os dados de gasto social como porcentagem do PIB foram gentilmente cedidos por George Avelino (Fundação Getulio Vargas - FGV-SP). São os mesmos utilizados em Avelino, Brown e Hunter (2005). Já os dados de gasto social como porcentagem do gasto público total foram construídos a partir da base de dados sobre gasto social da División de Desarrollo Social de la Comisión Económica para América Latina y el Caribe-Cepal.

10. Os dados foram extraídos do World Development Indicators, do Banco Mundial (The World Bank, 2001).

11. Variação anual. Os dados foram extraídos do World Development Indicators, do Banco Mundial (The World Bank, 2001).

12. O indicador representa a porcentagem da força de trabalho total extraída da Cepal.

13. O indicador representa a soma da exportação e da importação sobre o PPP, cujos dados foram extraídos do World Development Indicators (The World Bank, 2001).

14. Extraído do World Development Indicators (The World Bank, 2001). Quando a variável dependente é medida pelo gasto público total, a variável Expend representa o gasto total como porcentagem do PIB. Quando é medida pelo PIB, representa o gasto corrente anual.

15. Os dados foram extraídos do World Development Indicators (The World Bank, 2005).

16. Em número absoluto, dados extraídos do World Development Indicators (The World Bank, 2001).

17. Os dados dessa variável me foram gentilmente cedidos por Octavio Amorim Neto. 
18. Para a análise da América Latina, por falta de informação sobre a composição do gabinete ministerial em El Salvador, Guatemala, Honduras e República Dominicana, a classificação ideológica nesses países corresponde à do partido do presidente e à informação referente à natureza do governo se o partido do presidente conta com a maioria das cadeiras da Câmara dos Deputados.

19. Em seu artigo, Coppedge (1997) separa os sistemas partidários latino-americanos em blocos, observando seu desempenho em cada eleição. O autor examina quatro indicadores que caracterizam o sistema partidário: posição esquerda-direita; polarização esquerda-direita; volatilidade dos blocos ajustados; número de blocos efetivos. A posição esquerda-direita mede a distância média dos partidos de esquerda e de direita em cada eleição. A polarização esquerda-direita mede a dispersão dos votos de esquerda e de direita em relação ao centro. A volatilidade dos blocos ajustados mede a diferença de votos de partidos de esquerda e de direita de uma eleição para outra. Para a realização do teste, aos partidos de esquerda foi atribuído valor -1 ; aos de centro-esquerda, valor - 0,5 ; aos de centro, valor 0 ; aos de centro-direita, valor 0,5; e aos partidos de direita atribuiu-se valor 1 .

20. Os dados dessa variável me foram gentilmente cedidos por Hugo Borsani.

21. Média da estabilidade ministerial por ano. Ou seja, duração média, em dias, da permanência de todos os ministros nomeados pelo governo em um dado ano dividida por 365. De acordo com esse indicador, a estabilidade ministerial pode variar entre um mínimo de 0,003 (=1/365; situação extrema em que cada ministro permanece apenas um dia no cargo) e um máximo de 1 (quando permanece os 365 dias do ano).

22. Em inglês, pooled time series - cross-section analysis.

23. Os dados foram ordenados por país, ou seja, a segunda observação da base (anual) é a observação do país codificado com o número 1 (Argentina) no segundo período (ano). A observação seguinte à correspondente ao país $i$ no período t é a observação correspondente ao país $i$ no período $t+1$. A última observação do país $i$ é seguida pela primeira observação do país $i+1$. Não foram incluídas variáveis dummies para ano a fim de não criar problemas de perda de graus de liberdade, o que prejudica a precisão do modelo.

24. A inclusão de um valor defasado (auto-regressivo) da variável dependente implica que o valor dessa variável no ano $t$ esteja sendo explicado, em parte, pelo valor dessa variável no ano anterior ( $t-1$ ) (Beck e Katz, 1995).

25. Na escolha dos modelos econométricos, optou-se pelo modelo mais recorrente na ciência política nas análises similares às do presente artigo.

26. Uma interessante observação de um dos pareceristas, segundo o qual “parte dos países da América Latina rompeu o monopólio da representação pelos partidos políticos e, especialmente, os governos que se dizem de esquerda conquistaram o poder por meio de movimentos não-partidários, como ocorreu com Hugo Chávez, na Venezuela, e, mais recentemente, com Evo Morales, na Bolívia", de certa forma não afeta o argumento central deste texto. O que o estudo mostra é que, no período em análise (anos 1980 e 1990), existem variações importantes entre partidos políticos e políticas públicas. No contexto atual latino-americano, observa-se um fenômeno social complexo que repercutiu na política e redefiniu a natureza do conflito político, reconfigurando todo o sistema partidário. Na Bolívia, por exemplo, Evo Morales é eleito pelo Movimiento al Socialismo - MAS, que só no nome se trata de um movimento. 
Na verdade, o MAS é um partido com representação legislativa e que aos poucos foi consolidando sua força no sistema partidário boliviano. Na Venezuela de Hugo Chávez, de fato o Movimiento Quinta República - MQR passa a ter hegemonia em meados dos anos 1990, mas atualmente todo o bloco chavista se concentra em torno do Partido Socialista unificado, o que, mais uma vez, aponta para o interesse de, por meio de partidos, institucionalizar o conflito nesse país.

\section{REFERÊNCIAS BIBLIOGRÁFICAS}

ACHEN, Christopher H. (2000), Why Lagged Dependent Variables Can Suppress the Explanatory Power of the Independent Variables. Trabalho apresentado no Encontro Anual de Metodologia Política, da American Political Science Association - APSA, Los Angeles, 20-22 de julho.

ALESINA, Alberto e ROSENTHAL, Howard. (1995), Partisan Politics, Divided Government, and the Economy. New York, Cambridge University Press.

ALESINA, Alberto et alii. (1999), "Budget Institutions and Fiscal Performance in Latin America". Journal of Development Economics, vol. 59, no 2, pp. 253-273.

AMORIM NETO, Octavio e BORSANI, Hugo. (2004), “Presidents and Cabinets: The Political Determinants of Fiscal Behavior in Latin America". Studies in Comparative International Development, vol. 39, no 1, pp. 3-27.

AVELINO, George, BROWN, David S. e HUNTER, Wendy. (2005), “The Effect of Capital Mobility, Trade Openness, and Democracy on Social Spending". American Journal of Political Science, vol. 49, no 3, pp. 625-641.

BECK, Nathaniel e KATZ, Jonathan N. (1995), "What to Do (and Not to Do) with Time-Series Cross-Section Data". American Political Science Review, vol. 89, no 3, pp. 634-647.

BLAIS, André, BLAKE, Donald e DION, Stéphanie. (1993), “Do Parties Make a Difference? Parties and the Size of Government in Liberal Democracies". American Journal of Political Science, vol. 37, no 1, pp. 40-62.

BOIX, Carles. (1997), "Political Parties and the Supply Side of the Economy: The Provision of Physical and Human Capital in Advanced Economies, 1960-90". American Journal of Political Science, vol. 41, no 3, pp. 814-845.

BORSANI, Hugo. (2003), Eleições e Economia. Instituições Políticas e Resultados Macroeconômicos na América Latina (1979-1998). Belo Horizonte, Editora UFMG.

COPPEDGE, Michael. (1997), “A Classification of Latin American Political Parties". Working Paper, no 244, Kellog Institute, University of Notre Dame.

FIORINA, Morris. (1996), Divided Government. New York, Macmillan. 


\section{Cristiane Batista}

GARRETT, Geoffrey. (1998), Partisan Politics in the Global Economy. Cambridge, Cambridge University Press.

HALLERBERG, Mark e MARIER, Patrik. (2004), “Executive Authority, the Personal Vote, and Budget Discipline in Latin American and Caribbean Countries". American Journal of Political Science, vol. 48, no 3, pp. 571-587.

HICKS, Alexander e SWANK, Duane. (1984), “Government Redistribution in Rich Capitalist Democracies". Policy Studies Journal, no 13, pp. 265-286.

HUBER, Evelyne, MUSTILLO, Tom e STEPHENS, John D. (2004), Determinants of Social Spending in Latin America and the Caribbean. Trabalho apresentado no Encontro da Society for the Advancement of Socio-Economics, Washington, D.C., 8-11 de julho, e no congresso internacional da Latin American Studies Association - LASA, Las Vegas, 6-10 de outubro.

IVERSEN, Torben. (1996), "Power, Flexibility, and the Breakdown of Centralized Wage Bargaining". Comparative Politics, vol. 28, no 4, pp. 399-436.

JONES, Mark P., SANGUINETTI, Pablo e TOMMASI, Mariano. (1999), “Politics, Institutions, and Fiscal Performance in a Federal System: An Analysis of the Argentine Provinces". Journal of Development Economics, vol. 61, no 2, pp. 305-333.

KAUFMAN, Robert R. e SEGURA-UBIERGO, Alex. (2001), “Globalization, Domestic Politics, and Social Spending in Latin America: A Time-Series Cross-Section Analysis, 1973-1997". World Politics, vol. 53, no 4, pp. 553-587.

KITSCHELT, Herbert. (1994), The Transformation of European Social Democracy. New York, Cambridge University Press.

MEJÍA ACOSTA, Andrés e COPPEDGE, Michael. (2001), Political Determinants of Fiscal Discipline in Latin America, 1979-1998. Trabalho apresentado no XXIII Congresso Internacional da Latin American Studies Association - LASA, Washington, D.C., 5-8 de setembro. Disponível em http://www.internationalbudget.org/resources/ library/budgetLASA.pdf.

PIVEN, Frances Fox (ed.). (1991), Labor Parties in Postindustrial Societies. New York, Oxford University Press.

SCHARPF, Fritz. (1988), “Game Theoretical Interpretations of Inflation and Unemployment in Western Europe". Journal of Public Policy, vol. 7, no 3, pp. 227-257.

SWENSON, Peter. (1991), "Labor and the Limits of the Welfare State. The Politics of Intraclass Conflict and Cross-Class Alliances in Sweden and West Germany". Comparative Politics, vol. 23, no 4, pp. 379-399.

TSEBELIS, George. (1995), "Decision Making in Political Systems: Veto Players in Presidentialism, Parliamentarism, Multicameralism and Multipartyism". British Journal of Political Science, vol. 25, no 3, pp. 289-325.

TUFTE. Edward R. (1978), Political Control of the Economy. New Jersey, Princeton University Press.

WAWRO, Gregory. (2002), “Estimating Dynamic Panel Data Models in Political Science". Political Analysis, vol. 10, no 1, pp. 25-48. 


\section{ANEXO}

\section{ESTATÍSTICAS DESCRITIVAS DAS VARIÁVEIS DEPENDENTES E INDEPENDENTES}

Tabela 1

Gasto Social na América Latina: 1980-1999

\begin{tabular}{l|c|c|c|c}
\hline \multicolumn{5}{c}{ Gasto Social \% GPT } \\
\hline Países & Média & Desvio Padrão & Mínimo & Máximo \\
\hline Argentina & 26,07 & 2,54 & 21,37 & 28,85 \\
Bolívia & 27,54 & 6,68 & 18,09 & 35,05 \\
Brasil & 15,80 & 2,88 & 11,75 & 21,85 \\
Chile & 25,18 & 2,39 & 21,26 & 28,02 \\
Colômbia & 18,94 & 3,00 & 15,23 & 24,50 \\
Costa Rica & 32,76 & 10,92 & 20,96 & 50,10 \\
El Salvador & 18,43 & 4,54 & 12,71 & 26,81 \\
Equador & 23,88 & 2,76 & 18,26 & 28,89 \\
Guatemala & 23,51 & 2,29 & 18,40 & 26,57 \\
Honduras & 28,79 & 2,06 & 25,91 & 31,36 \\
Peru & 19,64 & 2,32 & 13,33 & 24,86 \\
República Dominicana & 21,77 & 2,85 & 16,92 & 25,76 \\
Uruguai & 20,08 & 1,01 & 17,66 & 21,23 \\
Venezuela & 21,40 & 2,38 & 14,25 & 24,97 \\
\hline
\end{tabular}

Elaboração da autora.

Tabela 2

Gasto Social na América Latina: 1980-1999

\begin{tabular}{l|c|c|c|c}
\hline \multicolumn{5}{c}{ Gasto Social \% PIB } \\
\hline Países & Média & Desvio Padrão & Mínimo & Máximo \\
\hline Argentina & 8,17 & 0,85 & 7,00 & 9,70 \\
Bolívia & 7,23 & 2,07 & 4,00 & 9,40 \\
Brasil & 3,63 & 0,75 & 2,60 & 4,80 \\
Chile & 5,54 & 0,71 & 4,50 & 6,80 \\
Colômbia & 5,59 & 1,58 & 4,20 & 8,80 \\
Costa Rica & 9,93 & 1,39 & 8,40 & 13,60 \\
El Salvador & 4,02 & 0,63 & 3,10 & 5,50 \\
Equador & 5,98 & 1,12 & 4,10 & 7,50 \\
Guatemala & 2,93 & 0,51 & 2,40 & 3,80 \\
Honduras & 6,68 & 0,52 & 5,80 & 7,60 \\
Peru & 3,26 & 0,67 & 2,00 & 4,40 \\
República Dominicana & 3,09 & 0,62 & 1,90 & 4,40 \\
Uruguai & 5,81 & 0,41 & 5,10 & 6,30 \\
Venezuela & 5,79 & 1,41 & 3,10 & 8,60 \\
\hline
\end{tabular}

Elaboração da autora. 
Tabela 3

Gasto em Educação na América Latina: 1980-1999

\begin{tabular}{l|c|c|c|c}
\hline \multicolumn{5}{c}{ Gasto em Educação \% GPT } \\
\hline Países & Média & Desvio Padrão & Mínimo & Máximo \\
\hline Argentina & 12,40 & 1,36 & 10,05 & 14,57 \\
Bolívia & 18,11 & 3,70 & 12,61 & 22,17 \\
Brasil & 5,27 & 1,03 & 3,91 & 7,08 \\
Chile & 14,04 & 1,64 & 11,92 & 16,43 \\
Colômbia & 12,76 & 1,27 & 11,10 & 14,84 \\
Costa Rica & 14,14 & 4,14 & 9,37 & 21,79 \\
El Salvador & 11,38 & 3,17 & 7,88 & 17,17 \\
Equador & 16,02 & 2,29 & 10,00 & 19,49 \\
Guatemala & 15,06 & 1,77 & 10,79 & 17,42 \\
Honduras & 18,05 & 1,17 & 16,25 & 20,00 \\
Peru & 13,87 & 2,12 & 10,30 & 19,21 \\
República Dominicana & 13,75 & 2,60 & 9,85 & 17,14 \\
Uruguai & 9,46 & 0,78 & 8,51 & 10,68 \\
Venezuela & 15,70 & 1,88 & 10,73 & 18,50 \\
\hline
\end{tabular}

Elaboração da autora.

Tabela 4

Gasto em Educação na América Latina: 1980-1999

\begin{tabular}{l|c|c|c|c}
\hline \multicolumn{5}{c}{ Gasto em Educação \% PIB } \\
\hline Países & Média & Desvio Padrão & Mínimo & Máximo \\
\hline Argentina & 3,89 & 0,48 & 3,30 & 4,90 \\
Bolívia & 4,04 & 1,57 & 1,40 & 6,20 \\
Brasil & 1,22 & 0,29 & 0,80 & 1,70 \\
Chile & 3,09 & 0,48 & 2,50 & 4,00 \\
Colômbia & 3,68 & 0,59 & 3,10 & 5,00 \\
Costa Rica & 4,46 & 0,57 & 3,70 & 6,20 \\
El Salvador & 2,48 & 0,46 & 1,90 & 3,50 \\
Equador & 4,19 & 0,95 & 2,60 & 5,60 \\
Guatemala & 1,88 & 0,33 & 1,40 & 2,40 \\
Honduras & 4,29 & 0,33 & 3,90 & 4,90 \\
Peru & 2,29 & 0,56 & 1,30 & 3,40 \\
República Dominicana & 1,91 & 0,45 & 1,10 & 2,90 \\
Uruguai & 2,77 & 0,34 & 2,30 & 3,40 \\
Venezuela & 4,26 & 1,13 & 2,30 & 6,50 \\
\hline
\end{tabular}

Elaboração da autora. 
Tabela 5

Gasto em Saúde na América Latina: 1980-1999

\begin{tabular}{l|c|c|c|c}
\hline \multicolumn{5}{c}{ Gasto em Saúde \% GPT } \\
\hline Países & Média & Desvio Padrão & Mínimo & Máximo \\
\hline Argentina & 13,67 & 1,32 & 11,32 & 15,41 \\
Bolívia & 9,42 & 3,09 & 4,69 & 12,88 \\
Brasil & 10,53 & 2,02 & 7,70 & 14,82 \\
Chile & 11,14 & 0,87 & 9,34 & 11,81 \\
Colômbia & 6,18 & 2,77 & 3,59 & 12,33 \\
Costa Rica & 18,63 & 6,91 & 11,21 & 29,17 \\
El Salvador & 7,05 & 1,67 & 4,61 & 9,65 \\
Equador & 7,86 & 2,03 & 6,19 & 12,81 \\
Guatemala & 8,45 & 0,66 & 7,61 & 10,13 \\
Honduras & 10,74 & 1,41 & 8,64 & 13,04 \\
Peru & 5,77 & 1,22 & 3,03 & 7,58 \\
República Dominicana & 8,02 & 0,86 & 6,27 & 9,48 \\
Uruguai & 10,62 & 1,04 & 8,67 & 21,23 \\
Venezuela & 5,70 & 0,93 & 3,51 & 7,76 \\
\hline
\end{tabular}

Elaboração da autora.

Tabela 6

Gasto em Saúde na América Latina: 1980-1999

\begin{tabular}{l|c|c|c|c}
\hline \multicolumn{5}{c}{ Gasto em Saúde \% PIB } \\
\hline Países & Média & Desvio Padrão & Mínimo & Máximo \\
\hline Argentina & 4,28 & 0,40 & 3,70 & 5,00 \\
Bolívia & 2,48 & 0,90 & 1,10 & 3,40 \\
Brasil & 2,42 & 0,50 & 1,70 & 3,20 \\
Chile & 2,45 & 0,24 & 2,00 & 2,80 \\
Colômbia & 1,91 & 1,08 & 1,10 & 4,10 \\
Costa Rica & 5,48 & 0,91 & 4,50 & 7,40 \\
El Salvador & 1,54 & 0,29 & 1,20 & 2,00 \\
Equador & 1,79 & 0,21 & 1,40 & 2,20 \\
Guatemala & 1,05 & 0,19 & 0,80 & 1,40 \\
Honduras & 2,38 & 0,30 & 1,90 & 3,00 \\
Peru & 0,97 & 0,22 & 0,60 & 1,30 \\
República Dominicana & 1,14 & 0,22 & 0,80 & 1,50 \\
Uruguai & 3,05 & 0,29 & 2,60 & 3,50 \\
Venezuela & 1,54 & 0,33 & 0,80 & 2,10 \\
\hline
\end{tabular}

Elaboração da autora. 
Tabela 7

PIB per capita na América Latina: 1980-1999

\begin{tabular}{l|c|c|c|c}
\hline \multicolumn{5}{c}{ PIB per capita (constant 1995 US\$) } \\
\hline Países & Média & Desvio Padrão & Mínimo & Máximo \\
\hline Argentina & $7.125,28$ & 803,55 & 5781,90 & $8.473,60$ \\
Bolívia & 870,23 & 60,61 & 794,11 & 972,24 \\
Brasil & $4.284,73$ & 187,94 & $3.984,30$ & $4.564,60$ \\
Chile & $4.383,90$ & 713,54 & $3.282,60$ & $5.246,60$ \\
Colômbia & $2.105,71$ & 215,12 & $1.834,60$ & $2.438,60$ \\
Costa Rica & $3.115,78$ & 385,26 & $2.634,40$ & $3.994,20$ \\
El Salvador & $1.486,16$ & 168,63 & $1.314,30$ & $1.752,20$ \\
Equador & $1.513,01$ & 53,11 & $1.386,60$ & $1.584,40$ \\
Guatemala & $1.413,77$ & 80,83 & $1.299,20$ & $1.545,40$ \\
Honduras & 693,53 & 17,19 & 665,29 & 722,65 \\
Peru & $2.268,34$ & 250,76 & $1.866,60$ & $2.682,90$ \\
República Dominicana & $1.471,22$ & 167,05 & $1.326,80$ & $1.916,40$ \\
Uruguai & $5.358,95$ & 690,40 & $4.157,50$ & $6.460,90$ \\
Venezuela & $3.541,53$ & 190,62 & $3.213,40$ & $3.991,20$ \\
\hline
\end{tabular}

Elaboração da autora.

Tabela 8

Índice de Inflação na América Latina: 1980-1999

\begin{tabular}{l|c|c|c|c}
\hline \multicolumn{5}{c}{ Inflação (anual \%) } \\
\hline Países & Média & Desvio Padrão & Mínimo & Máximo \\
\hline Argentina & 443,87 & 874,07 & $-2,00$ & $3.057,60$ \\
Bolívia & 26,82 & 58,69 & 2,79 & 230,10 \\
Brasil & 719,75 & 883,71 & 3,91 & $2.509,50$ \\
Chile & 9,88 & 7,17 & 1,71 & 21,24 \\
Colômbia & 23,80 & 6,83 & 12,52 & 45,36 \\
Costa Rica & 22,28 & 16,24 & 10,15 & 84,17 \\
El Salvador & 12,42 & 7,78 & 0,53 & 33,29 \\
Equador & 36,67 & 15,42 & 14,35 & 70,78 \\
Guatemala & 15,80 & 12,53 & 5,20 & 41,46 \\
Honduras & 12,86 & 8,97 & 2,83 & 28,89 \\
Peru & 598,40 & 1647,82 & 3,85 & $6.837,00$ \\
República Dominicana & 17,96 & 17,73 & 3,51 & 58,25 \\
Uruguai & 54,94 & 31,29 & 4,82 & 106,84 \\
Venezuela & 33,11 & 28,82 & $-1,20$ & 115,52 \\
\hline
\end{tabular}

Elaboração da autora. 
Tabela 9

Desemprego na América Latina: 1980-1999

\begin{tabular}{l|c|c|c|c}
\hline \multicolumn{5}{c}{ Desemprego (\% da força de trabalho total) } \\
\hline Países & Média & Desvio Padrão & Mínimo & Máximo \\
\hline Argentina & 9,09 & 4,22 & 4,40 & 16,30 \\
Bolívia & 6,30 & 2,55 & 3,10 & 11,60 \\
Brasil & 5,09 & 1,80 & 2,40 & 7,80 \\
Chile & 5,38 & 0,86 & 4,40 & 7,20 \\
Colômbia & 10,52 & 2,16 & 7,60 & 15,00 \\
Costa Rica & 5,85 & 1,63 & 3,80 & 9,40 \\
El Salvador & 9,56 & 3,04 & 7,50 & 16,90 \\
Equador & 8,03 & 1,91 & 5,70 & 11,50 \\
Guatemala & - & - & - & - \\
Honduras & 7,04 & 3,13 & 3,20 & 12,10 \\
Peru & 7,95 & 1,70 & 4,80 & 10,90 \\
República Dominicana & 14,09 & 4,81 & 8,00 & 20,30 \\
Uruguai & 9,79 & 1,51 & 8,00 & 13,10 \\
Venezuela & 9,51 & 2,20 & 5,90 & 13,10 \\
\hline
\end{tabular}

Elaboração da autora.

Tabela 10

Índice de Abertura Comercial na América Latina: 1980-1999

\begin{tabular}{l|c|c|c|c}
\hline \multicolumn{5}{c}{ PPPbas (Exportação + Importação / PPP) } \\
(constant 1995 US\$) \\
\hline Países & Média & Desvio Padrão & Mínimo & Máximo \\
\hline Argentina & 255381725119,48 & 596132775319,03 & 43585714285,71 & 2051710000000,00 \\
Bolívia & 5357241585,66 & 667323458,20 & 4317322834,65 & 6743456790,12 \\
Brasil & 774307938507,61 & 1552279321210,36 & 159407407407,41 & 4293450000000,00 \\
Chile & 24056795271,92 & 3159603471,16 & 19953146313,98 & 28539724811,36 \\
Colômbia & 167817620851,14 & 122456319751,62 & 42371551426,51 & 476415662650,60 \\
Costa Rica & 17675660152,94 & 12943621763,59 & 9008556238,58 & 62693843594,01 \\
El Salvador & 9833813165,11 & 2586226598,38 & 6898010204,08 & 16090714285,71 \\
Equador & 1025928782,05 & 1261954312,00 & 25333425,47 & 4022882693,32 \\
Guatemala & 611994002,41 & 150397298,98 & 483653846,15 & 868809523,81 \\
Honduras & 2089326004,02 & 815682595,52 & 759652509,65 & 3172164948,45 \\
Peru & 52177245292,50 & 64907749964,29 & 24485430463,58 & 234487500000,00 \\
República & & & & \\
Dominicana & 37186170071,46 & 30503163486,29 & 9983762886,60 & 99875000000,00 \\
Uruguai & 437561818,81 & 649481910,41 & 29477955,67 & 2051850000,00 \\
Venezuela & 16423326820,28 & 13848717759,79 & 674294670,85 & 39368635437,88 \\
\hline
\end{tabular}

Elaboração da autora. 
Tabela 11

Gasto Público Total na América Latina (\% PIB): 1980-1999

\begin{tabular}{l|c|c|c|c}
\hline \multicolumn{5}{c}{ Gasto Público Total (\% PIB) } \\
\hline Países & Média & Desvio Padrão & Mínimo & Máximo \\
\hline Argentina & 13,73 & 2,53 & 9,42 & 17,68 \\
Bolívia & 19,05 & 4,16 & 12,42 & 24,03 \\
Brasil & 29,84 & 4,77 & 24,36 & 37,25 \\
Chile & 21,33 & 1,18 & 19,85 & 24,00 \\
Colômbia & 14,42 & 1,71 & 11,53 & 18,75 \\
Costa Rica & 20,27 & 2,42 & 14,62 & 24,35 \\
El Salvador & 15,69 & 0,86 & 15,08 & 16,29 \\
Equador & 14,81 & 1,01 & 13,13 & 16,20 \\
Guatemala & - & - & - & - \\
Honduras & - & - & - & - \\
Peru & 17,99 & 1,28 & 11,08 & 20,63 \\
República Dominicana & 14,71 & 1,89 & 11,08 & 17,34 \\
Uruguai & 27,43 & 3,28 & 23,35 & 32,58 \\
Venezuela & 20,26 & 2,05 & 16,86 & 25,23 \\
\hline
\end{tabular}

Elaboração da autora.

Tabela 12

Gasto Público Total na América Latina (corrente): 1980-1999

\begin{tabular}{l|c|c|c|c}
\hline \multicolumn{5}{|c}{ Gasto Público Corrente } \\
\hline Países & Média & Desvio Padrão & Mínimo & Máximo \\
\hline Argentina & 20162492660,00 & 19583226243,55 & 88500,00 & 45930000000,00 \\
Bolívia & 5298721428,57 & 3554001484,61 & 1010000000,00 & 11167000000,00 \\
Brasil & 30622411123,22 & 70134889889,29 & 127,75 & 2134800000000,00 \\
Chile & 4953170000000,00 & 2153123873739,43 & 1884500000000,00 & 8237000000000,00 \\
Colômbia & 6602800000000,00 & 8598306745241,37 & 211200000000,00 & 285360000000000,00 \\
Costa Rica & 2577680000000,00 & 288778415463,99 & 10370000000,00 & 966890000000,00 \\
El Salvador & 16795500000,00 & 1383807970,78 & 15817000000,00 & 17774000000,00 \\
Equador & 1207401466666,67 & 1760534243239,41 & 41698000000,00 & 5717000000000,00 \\
Guatemala & - & - & - & - \\
Honduras & - & - & - & - \\
Peru & 9673381108,47 & 12376941791,63 & 1943,00 & 34168000000,00 \\
República & & & & \\
Dominicana & 12175768421,05 & 12802516326,40 & 1077200000,00 & 39419000000,00 \\
Uruguai & 24149360000,00 & 28099583891,06 & 118410000,00 & 76079000000,00 \\
Venezuela & 2253529150000,00 & 3819719295375,49 & 55819000000,00 & 120960000000000,00 \\
\hline
\end{tabular}

Elaboração da autora. 
Tabela 13

Dependência Demográfica na América Latina: 1980-1999

\begin{tabular}{l|c|c|c|c}
\hline \multicolumn{5}{c}{ \% Dependentes sobre População Economicamente Ativa } \\
\hline Países & Média & Desvio Padrão & Mínimo & Máximo \\
\hline Argentina & 0,64 & 0,02 & 0,60 & 0,65 \\
Bolívia & 0,81 & 0,02 & 0,78 & 0,84 \\
Brasil & 0,61 & 0,05 & 0,53 & 0,69 \\
Chile & 0,56 & 0,01 & 0,55 & 0,57 \\
Colômbia & 0,69 & 0,06 & 0,60 & 0,80 \\
Costa Rica & 0,68 & 0,04 & 0,61 & 0,74 \\
El Salvador & 0,80 & 0,08 & 0,68 & 0,91 \\
Equador & 0,76 & 0,08 & 0,63 & 0,88 \\
Guatemala & 0,94 & 0,03 & 0,87 & 0,97 \\
Honduras & 0,92 & 0,05 & 0,83 & 0,98 \\
Peru & 0,73 & 0,06 & 0,64 & 0,83 \\
República Dominicana & 0,70 & 0,07 & 0,61 & 0,83 \\
Uruguai & 0,60 & 0,00 & 0,60 & 0,60 \\
Venezuela & 0,71 & 0,04 & 0,63 & 0,78 \\
\hline
\end{tabular}

Elaboração da autora.

Tabela 14

População Urbana na América Latina: 1980-1999

\begin{tabular}{l|c|c|c|c}
\hline \multicolumn{5}{c}{ População Urbana (Total) } \\
\hline Países & Média & Desvio Padrão & Mínimo & Máximo \\
\hline Argentina & 28946062,5 & 2407449,175 & 25201000 & 32776000 \\
Bolívia & 4037864,286 & 626588,7556 & 3099600 & 5037400 \\
Brasil & 116027933,3 & 12817888,62 & 95603000 & 135580000 \\
Chile & 11879400 & 647840,0351 & 10911000 & 12831000 \\
Colômbia & 24129500 & 3831137,23 & 18178000 & 30523000 \\
Costa Rica & 1349950 & 225693,6757 & 984400 & 1708400 \\
El Salvador & 2345129,412 & 277530,991 & 1986800 & 2848000 \\
Equador & 5683710 & 1320367,759 & 3741700 & 7980900 \\
Guatemala & 3623535,714 & 440372,9549 & 3004400 & 4377700 \\
Honduras & 2188088,889 & 603428,5385 & 1371800 & 3263700 \\
Peru & 14873157,89 & 2080385,842 & 11556000 & 18272000 \\
República Dominicana & 4097700 & 792307,2298 & 2877000 & 5409100 \\
Uruguai & 2812473,333 & 126776,5608 & 2623800 & 3016200 \\
Venezuela & 16151750 & 2692531,383 & 11982000 & 20535000 \\
\hline
\end{tabular}

Elaboração da autora. 


\section{ABSTRACT}

Political Parties, Ideology, and Social Policy in Latin America: 1980-1999

The objective of this article was to investigate whether the ideology of governing parties in Latin America affects social policies, in a context of globalization under which, according to the literature, national states have lost their decision-making autonomy. The article's main hypothesis is that - all else remaining equal - governments with a leftist majority invest more in social policies than other governments, especially those with a rightist majority. The methodology used to test the hypothesis was econometric analysis of panel data, also known as pooled time series/cross-section analysis. Estimation of the model's parameters used the "panel corrected standard error" method suggested by Beck and Katz for the analysis of panels with similar dimensions to those of the current study. The principal findings of the econometric analyses corroborated the article's main hypothesis, according to which governments with a leftist majority invest more in the social area.

Key words: social policies; Latin America; pooled time series

\section{RÉSUMÉ}

Partis Politiques, Idéologie et Politique Sociale en Amérique Latine: 1980-1999

Dans cet article, on cherche à savoir si, en Amérique latine, l'idéologie des partis au gouvernement touche les politiques sociales, dans un contexte de mondialisation où, selon la littérature, les états nationaux ont perdu leur autonomie de décision. L'hypothèse principale est que, dans des conditions identiques, les gouvernements de gauche majoritaires s'occupent davantage de politique sociale que les autres gouvernements, surtout ceux de droite. On a utilisé comme méthodologie l'analyse économétrique de panel, appelée aussi "séries agrégées" (pooled time series - cross section analysis). Pour évaluer les paramètres du modèle, on a considéré la méthode OLS avec erreur-type corrigée, tel que le suggèrent Beck et Katz pour des analyses de panel aux dimensions semblables à celles de cette étude. Les principaux résultats des analyses économétriques confirment que les gouvernements majoritaires de gauche investissent plus dans le domaine social.

Mots-clé: politique sociale; Amérique Latine 